\title{
Uma reflexão sobre o uso das modalidades de tradução no contexto jurídico
}

\section{A reflection about translation modalities on juridical translation}

\author{
Maysa Vani Alves*
}

Resumo: Este artigo tem como objetivo apresentar um estudo de caso, a partir do modelo de AUBERT (2006), para refletir sobre as modalidades, analisando seu uso em relação aos marcadores culturais e observando quais modalidades são mais usadas no contexto jurídico. Para isso, foi extraído um corpus da lei francesa sobre o divórcio, bem como um corpus correspondente na lei brasileira.

Palavras-chave: modalidades de tradução; marcadores culturais; lei sobre o divórcio; Brasil; França.

Abstract: This article presents a case study to reflect about the translation modalities AUBERT (2006), analyzing its usage in relation to the cultural markers, observing which modalities are the most used in the juridical context. To do this, a corpus has been extracted from the French divorce Law, as well as a correspondent corpus of the Brazilian divorce Law.

Keywords: translation modalities; cultural markers; divorce Law; Brazil; France.

\footnotetext{
* Mestranda do curso Estudos da Tradução na Universidade de São Paulo
} 
ALVES, M. V. - Uma reflexão sobre o uso das modalidades de tradução no contexto jurídico

\section{Introdução}

O tradutor juramentado, em geral, não é especialista jurídico, fazendo com que existam frequentemente muitas dúvidas em relação à terminologia correta a ser aplicada na tradução de determinados documentos. Além de não ser especialista e ter dificuldades relacionadas a terminologias específicas, normalmente, o tradutor juramentado encontra dificuldades ao traduzir termos marcados culturalmente, que, dependendo do grau de afastamento entre as culturas em questão, nem sempre possuirão um equivalente plenamente satisfatório na tradução, pois, segundo ZavagLIA e PoPPI (2012), a linguagem jurídica é diferente de outras linguagens técnicas devido ao fato de estar inserida em um contexto nacional específico.

Nesse sentido, este artigo tem como escopo apresentar uma reflexão sobre 0 uso das modalidades de tradução (AUBERT 2006) aplicadas a alguns termos fixos presentes nos artigos das leis sobre divórcio no Brasil e na França, buscando analisar se há a preponderância de determinado tipo de modalidade de tradução, visto que os textos jurídicos são conhecidos por apresentarem muitos marcadores culturais.

\section{Questões teóricas}

\subsection{0 divórcio na França e no Brasil}

As leis brasileira e francesa sobre o divórcio divergem em alguns pontos, o que pode ser um fator que demonstra a existência de diferenças culturais, podendo haver, assim, a presença de marcadores culturais em ambas as leis. 
ALVES, M. V. - Uma reflexão sobre o uso das modalidades de tradução no contexto jurídico

Para os dois países, o divórcio possui o mesmo significado, ou seja, é a dissolução de um casamento válido, que ocorre mediante sentença judicial, permitindo que as pessoas envolvidas contraiam novo matrimônio. No Brasil, o divórcio era obtido após um ano de separação judicial, o que foi modificado pela Emenda Constitucional 66, que estabelece que a separação judicial não é mais necessária para a obtenção do divórcio.

Segundo a lei o 6.515 de 26 de dezembro de $1977^{1}$, a sociedade conjugal, no Brasil, pode ser encerrada por quatro motivos: pela morte de um dos cônjuges, pela nulidade ou anulação do casamento, por separação judicial e pelo divórcio, sendo que há dois tipos de divórcio, o litigioso e o consensual. Em caso de divórcio, segundo o artigo 26 dessa mesma lei, o cônjuge que teve a iniciativa continuará com o dever de assistência ao outro, o sobrenome poderá ou não ser alterado e os direitos e deveres dos pais em relação aos filhos não serão modificados.

Na França, o divórcio existe desde 1792 e pode, segundo o site da Rede J udiciária Europeia, ser requerido mediante quatro modalidades: o divorce par consentement mutuel, o divorce accepté, o divorce pour altération définitive du lien conjugal e o divorce pour faute. Diferentemente do Brasil, o divórcio na França põe fim à obrigação ao suporte ao cônjuge, exceto se decretado por ruptura da vida em comum, que, no caso, mantém a obrigação de suporte ao cônjuge que não solicitou o divórcio. Nas outras modalidades, uma pensão poderá ser solicitada para compensar uma possível disparidade monetária causada pela ruptura do matrimônio. Em relação aos filhos advindos da união, o casal permanece com seus deveres para com os filhos, devendo contribuir para a educação dos mesmos de acordo com seus recursos financeiros, conforme afirma 0 artigo 371-2 do Chapitre 1er du titre IX, e essa obrigação deve ser mantida até a maioridade deles.

\footnotetext{
${ }^{1}$ As leis brasileira e francesa sobre o divórcio podem ser consultadas na seção "Anexos".
} 
ALVES, M. V. - Uma reflexão sobre o uso das modalidades de tradução no contexto jurídico

\subsection{As modalidades de tradução: o modelo descritivo de Aubert}

As modalidades que serão resumidamente explanadas constam nos eixos da literalidade e da equivalência. O eixo da literalidade é o eixo em que se encontram as modalidades relacionadas à tradução direta. E, para fins desse artigo, serão apresentadas duas modalidades desse eixo:

Tradução palavra por palavra: segundo AUBERT (2006), a tradução palavra por palavra ocorre quando são observadas quatro características específicas na comparação do texto fonte e do texto-alvo. Essas características são: (i) a existência do mesmo número de palavras; (ii) a mesma ordem sintática presente nos textos fonte e alvo; (iii) a aplicação das mesmas categorias gramaticais do texto fonte no texto-alvo; e, por fim, (iv) a existência de opções lexicais tidas, no contexto, por sinônimos interlinguais.

Transposição: sempre que um dos critérios acima mencionados não for satisfeito, ocorre a transposição, ou seja, a transposição é a modalidade que apresenta rearranjos morfossintáticos. Assim, se duas ou mais palavras forem mescladas umas com as outras, se uma única palavra for desdobrada em mais de uma ou se a ordem das palavras for alterada, teremos transposição.

Outro eixo tradutório definido por AUBERT (2006) é o da equivalência. Esse eixo apresenta modalidades nas quais há mais evidência da coautoria do tradutor, assim sendo, elas apresentam diversas formas de deslocamento, podendo tornar o texto uma reescrita interpretativa.

Modulação: essa modalidade é um tanto quanto complexa de se caracterizar e de se identificar em um texto traduzido, pois, a modulação ocorre quando há uma modificação na estrutura semântica do texto-alvo, mantendo-se, contudo, o sentido no contexto. A modulação é "o recurso tradutório que gera uma forma de conteúdo discrepante, mas que retém uma clara equivalência na substância de conteúdo" (AUBERT 2006: 62). Ao usar essa modalidade, o tradutor busca manter o mesmo sentido do texto original. Assim, a modulação é frequentemente usada na substituição de expressões 
ALVES, M. V. - Uma reflexão sobre o uso das modalidades de tradução no contexto jurídico

metafóricas, ditados populares e figuras de linguagem, e, além disso, também pode ser vista em deslocamentos de registro, como ao traduzir um texto coloquial transformando-o em um texto formal.

Devido a essas resumidas características peculiares dessa modalidade tradutória, a modulação é particularmente relevante na tradução de textos literários e jurídicos, pois são gêneros que apresentam em seu conteúdo marcadores culturais.

\section{Análise}

Os trechos dos artigos da lei francesa foram selecionados da seguinte maneira: a palavra divorce foi inserida no campo de busca (usando o comando crtl + F) da lei sobre o divórcio francesa ${ }^{2}$, no site legifrance.gouv.fr. 0 site retornou 89 ocorrências com a palavra divorce. Todas as ocorrências da palavra divorce foram analisadas quanto a serem ou não termos fixos usados no contexto em questão. Foram, então, escolhidos somente os termos fixos que estavam relacionados ao contexto do divórcio, totalizando 15 termos. Após a seleção dos termos da lei francesa, buscou-se na lei brasileira sobre o divórcio ${ }^{3}$ trechos que possuíam o termo divórcio inserido nos mesmos contextos do francês e, quando tal não era encontrado, foi sugerida uma tradução. Em seguida, com o auxílio do modelo de AUBERT (2006), os termos encontrados foram classificados, buscando observar como algumas modalidades marcam 0 distanciamento ou aproximação cultural entre as duas línguas.

Para a reflexão em relação a esse modelo, as seguintes etapas foram realizadas: foi selecionado o corpus da lei francesa e o da lei brasileira; as ocorrências foram analisadas a partir das modalidades e foi feita uma contagem das modalidades em porcentagem. Tendo isso concluído, foi feita a

\footnotetext{
${ }^{2}$ Lol n ${ }^{\circ} 2004-439$ du 26 mai 2004 relative au divorce.

${ }^{3}$ LEI № 6.515, DE 26 DE DEZEMBRO DE 1977.
} 
ALVES, M. V. - Uma reflexão sobre o uso das modalidades de tradução no contexto jurídico

interpretação qualitativa dos dados, ou seja, uma análise dos termos encontrados, buscando observar os fatores e aspectos marcados culturalmente entre os termos das duas línguas.

Para iniciar a análise, o seguinte quadro será considerado:

\begin{tabular}{|l|c|c|c|c|c|}
\hline & $\begin{array}{c}\text { Palavra } \\
\text { por } \\
\text { palavra }\end{array}$ & Modulação & Transposição & $\begin{array}{c}\text { Modulação + } \\
\text { transposição }\end{array}$ & TOTAL \\
\hline Ocorrências & 11 & 2 & 0 & 2 & 15 \\
\hline & $73,35 \%$ & $13,3 \%$ & $0 \%$ & $13,35 \%$ & $100 \%$ \\
\hline
\end{tabular}

A partir da tabela pode-se confirmar que, devido às divergências entre os dois sistemas jurídicos, alguns termos foram enquadrados no eixo da equivalência, sendo 13,35\% atribuídos à modulação ocorrendo juntamente com a transposição e 13,3\% de ocorrência de modulação. Mais da metade, ou seja, $73,35 \%$ das ocorrências estão relacionadas ao eixo da literalidade, ocorrendo na classificação palavra por palavra.

Os dois casos de modulação ocorrendo juntamente com a transposição se devem a diferenças nos sistemas jurídicos dos países e, dentre essas duas ocorrências, em uma delas não foi encontrado o termo equivalente no português, logo, uma tradução foi sugerida.

Os termos modulados e transpostos são os seguintes:

\begin{tabular}{|c|c|c|c|c|}
\hline $\begin{array}{c}\text { Termo } \\
\text { (francês) }\end{array}$ & Contexto & $\begin{array}{c}\text { Termo } \\
\text { (português) }\end{array}$ & Contexto & $\begin{array}{l}\text { Tradução } \\
\text { sugerida }\end{array}$ \\
\hline $\begin{array}{c}\text { Article } 7 \text { - II: } \\
\text { Art. } 247 \text { : } \\
\text { Divorce par } \\
\text { consentement } \\
\text { mutuel }\end{array}$ & $\begin{array}{c}\text { Les époux } \\
\text { peuvent, à tout } \\
\text { moment de la } \\
\text { procédure, } \\
\text { demander au } \\
\text { juge de constater } \\
\text { leur accord pour } \\
\text { voir prononcer } \\
\text { leur divorce par } \\
\text { consentement }\end{array}$ & $\begin{array}{c}\text { Artigo 40: } \\
\text { 20 } \\
\text { Divórcio } \\
\text { consensual }\end{array}$ & $\begin{array}{c}\text { No divórcio } \\
\text { consensual, o } \\
\text { procedimento } \\
\text { adotado será o } \\
\text { previsto nos } \\
\text { artigos } 1.120 \text { a } \\
1.124 \text { do } \\
\text { Código de } \\
\text { Processo Civil }\end{array}$ & ---- \\
\hline
\end{tabular}


ALVES, M. V. - Uma reflexão sobre o uso das modalidades de tradução no contexto jurídico

\begin{tabular}{|c|c|c|c|c|}
\hline & $\begin{array}{c}\text { mutuel en lui } \\
\text { présentant une } \\
\text { convention } \\
\text { réglant les } \\
\text { conséquences de } \\
\text { celui-ci. }\end{array}$ & & & \\
\hline $\begin{array}{c}\text { Article 3 - I: } \\
\text { Divorce } \\
\text { accepté }\end{array}$ & $\begin{array}{c}\text { L'intitulé de la } \\
\text { section 2 du } \\
\text { chapitre ler du } \\
\text { titre VI du livre } \\
\text { ler du code civil } \\
\text { est ainsi rédigé : } \\
\text { " Du divorce } \\
\text { accepté » }\end{array}$ & -.-- & \multirow{2}{*}{ Divórcio } \\
& & & por aceite \\
\hline
\end{tabular}

O primeiro termo da tabela, Divorce par consentement mutuel, é uma modalidade de divórcio em que ambas as partes estão de acordo, o que poderia ser facilmente relacionado ao divórcio consensual da lei brasileira. Como há uma semelhança, nesse caso foi possível encontrar um termo equivalente, "divórcio consensual", que, em relação às modalidades de AUBeRT (2006), é claramente classificado como modulação juntamente com transposição.

0 segundo termo, divorce accepté, também ocorre quando o divórcio é consensual, mas, no caso, a diferença é que o pedido de divórcio pode ser feito por ambas as partes ou apenas por um dos cônjuges, diferentemente do divorce par consentement mutuel, que deve ser requerido pelas duas partes em conjunto. Como não há uma modalidade de divórcio equivalente a essa que esteja descrita na lei brasileira sobre o divórcio, não foi encontrado um termo equivalente e, por isso, foi proposta uma tradução, "divórcio por aceite".

Das ocorrências que foram apenas moduladas, o seguinte quadro pode ser observado:

\begin{tabular}{|c|c|c|c|c|}
\hline $\begin{array}{c}\text { Termo } \\
\text { (francês) }\end{array}$ & Contexto & $\begin{array}{c}\text { Termo } \\
\text { (português) }\end{array}$ & Contexto & $\begin{array}{c}\text { Tradução } \\
\text { sugerida }\end{array}$ \\
\hline & $\begin{array}{c}\text { Le juge cherche } \\
\text { à concilier les }\end{array}$ & & $\begin{array}{c}\text { A reconciliação } \\
\text { em nada }\end{array}$ & \\
\hline
\end{tabular}


ALVES, M. V. - Uma reflexão sobre o uso das modalidades de tradução no contexto jurídico

\begin{tabular}{|c|c|c|c|}
\hline $\begin{array}{c}\text { Article } 11 \text { - II: } \\
\mathbf{2 0} \\
\text { Concilier les } \\
\text { époux }\end{array}$ & $\begin{array}{l}\text { époux tant sur } \\
\text { le principe du } \\
\text { divorce que sur } \\
\text { ses } \\
\text { conséquences. }\end{array}$ & $\begin{array}{c}\text { Art. } 46 \\
\text { Parágrafo } \\
\text { único: } \\
\text { Reconciliação }\end{array}$ & $\begin{array}{l}\text { prejudicará os } \\
\text { direitos de } \\
\text { terceiros, } \\
\text { adquiridos antes } \\
\text { e durante a } \\
\text { separação, seja } \\
\text { qual for o } \\
\text { regime de bens. }\end{array}$ \\
\hline $\begin{array}{c}\text { Article } 11 \text { - IV: } \\
\text { Art. 252-3 } \\
\text { Projet de } \\
\text { règlement }\end{array}$ & $\begin{array}{l}\text { Il leur demande } \\
\text { de présenter } \\
\text { pour l'audience } \\
\text { de jugement un } \\
\text { projet de } \\
\text { règlement des } \\
\text { effets du } \\
\text { divorce. }\end{array}$ & $\begin{array}{c}\text { Seção I - Art 70 } \\
\S 20: \text { Partilha } \\
\text { de bens }\end{array}$ & $\begin{array}{l}\text { A partilha de } \\
\text { bens poderá ser } \\
\text { feita mediante } \\
\text { proposta dos } \\
\text { cônjuges e } \\
\text { homologada } \\
\text { pelo juiz ou por } \\
\text { este decidida. }\end{array}$ \\
\hline
\end{tabular}

A primeira ocorrência de modulação do quadro acima é concilier les époux, ou seja, reconciliar os cônjuges, e o termo encontrado na lei brasileira foi "reconciliação". Apesar da diferença, a tradução mantém o mesmo sentido, assim, essa ocorrência pode ser classificada como modulação.

0 segundo e último termo, projet de règlement, poderia ser traduzido literalmente por "projeto de liquidação/acerto de contas". O termo trata de uma etapa do divórcio, segundo o site legifrance.com, em que o juiz encarrega um escrivão ou profissional qualificado a estabelecer um projet de règlement sobre as pensões e obrigações após o divórcio. Essa ocorrência pode ser comparada com a "partilha de bens" da lei sobre o divórcio brasileira, que também ocorre após o divórcio e é a divisão do patrimônio do casal, de acordo com o regime de bens escolhido pelos ex-cônjuges. Assim, a equivalência entre os termos foi classificada como modulação.

No que tange 0 eixo da literalidade, 0 seguinte quadro pode ser observado: 
ALVES, M. V. - Uma reflexão sobre o uso das modalidades de tradução no contexto jurídico

\begin{tabular}{|c|c|c|c|c|}
\hline $\begin{array}{c}\text { Termo } \\
\text { (francês) }\end{array}$ & Contexto & $\begin{array}{c}\text { Termo } \\
\text { (português) }\end{array}$ & Contexto & $\begin{array}{l}\text { Tradução } \\
\text { sugerida }\end{array}$ \\
\hline $\begin{array}{l}\text { Article } 2 \text { - Il: } \\
\text { Art. } 232 \\
\text { Prononcer le } \\
\text { divorce }\end{array}$ & $\begin{array}{c}\text { Il peut refuser } \\
\text { I'homologation et ne pas } \\
\text { prononcer le divorce s'il } \\
\text { constate que la } \\
\text { convention préserve } \\
\text { insuffisamment les } \\
\text { intérêts des enfants ou } \\
\text { de l'un des époux. }\end{array}$ & $\begin{array}{l}\text { Art. } 31 \\
\text { Decretar o } \\
\text { divórcio }\end{array}$ & $\begin{array}{l}\text { Não se decretará o } \\
\text { divórcio se ainda } \\
\text { não houver } \\
\text { sentença } \\
\text { definitiva de } \\
\text { separação } \\
\text { judicial, ou se } \\
\text { esta não tiver } \\
\text { decidido sobre a } \\
\text { partilha dos bens. }\end{array}$ & \\
\hline $\begin{array}{l}\text { Article } 17 \text { - II: } \\
\text { Art. } 266 \\
\text { Action en } \\
\text { divorce }\end{array}$ & $\begin{array}{l}\text { Cette demande ne peut } \\
\text { être formée qu'à } \\
\text { l'occasion de l'action en } \\
\text { divorce. }\end{array}$ & $\begin{array}{l}\text { Art. } 40 \\
\text { Ação de } \\
\text { divórcio }\end{array}$ & $\begin{array}{c}\text { No caso de } \\
\text { separação de fato, } \\
\text { e desde que } \\
\text { completados } 2 \\
\text { (dois) anos } \\
\text { consecutivos, } \\
\text { poderá ser } \\
\text { promovida ação de } \\
\text { divórcio, na qual } \\
\text { deverá ser } \\
\text { comprovado } \\
\text { decurso do tempo } \\
\text { da separação }\end{array}$ & \\
\hline $\begin{array}{l}\text { Article 8: } \\
\text { Demande en } \\
\text { divorce }\end{array}$ & $\begin{array}{c}\text { Si une demande en } \\
\text { divorce doit être formée } \\
\text { au nom d'un maj eur en } \\
\text { tutelle, elle est } \\
\text { présentée par le tuteur, } \\
\text { avec l'autorisation du } \\
\text { conseil de famille s'il a } \\
\text { été institué ou du juge } \\
\text { des tutelles. }\end{array}$ & $\begin{array}{l}\text { Artigo } 40 \S \\
2 \stackrel{0}{ } \text { III } \\
\text { Pedido de } \\
\text { divórcio }\end{array}$ & $\begin{array}{l}\text { Se houver prova } \\
\text { testemunhal, ela } \\
\text { será produzida na } \\
\text { audiência de } \\
\text { ratificação do } \\
\text { pedido de divórcio } \\
\text { a qual será } \\
\text { obrigatoriamente } \\
\text { realizada. }\end{array}$ & ----- \\
\hline $\begin{array}{l}\text { Article } 11-\text { IV: } \\
\text { Art. 252-3 } \\
\text { Conséquences } \\
\text { du divorce }\end{array}$ & $\begin{array}{l}\text { Lorsque le juge constate } \\
\text { que le demandeur } \\
\text { maintient sa demande, il } \\
\text { incite les époux à régler } \\
\text { les conséquences du } \\
\text { divorce à l'amiable. }\end{array}$ & ---- & ---- & $\begin{array}{l}\text { Consequências } \\
\text { do divórcio }\end{array}$ \\
\hline $\begin{array}{l}\text { Chapitre II: } \\
\text { Procédure du } \\
\text { divorce }\end{array}$ & $\begin{array}{l}\text { Chapitre II: De la } \\
\text { procédure du divorce }\end{array}$ & & & $\begin{array}{l}\text { Processo de } \\
\text { divórcio }\end{array}$ \\
\hline
\end{tabular}


ALVES, M. V. - Uma reflexão sobre o uso das modalidades de tradução no contexto jurídico

\begin{tabular}{|c|c|c|c|c|}
\hline $\begin{array}{l}\text { Article 13- I } \\
\text { Instance en } \\
\text { divorce }\end{array}$ & $\begin{array}{c}\text { De l'introduction de } \\
\text { l'instance en divorce », } \\
\text { qui comprend les articles } \\
257-1,257-2 \text { et } 258 \text {. }\end{array}$ & $\begin{array}{l}\text { Art. } 180-\mathrm{V} \\
\text { Sentença de } \\
\text { divórcio }\end{array}$ & $\begin{array}{l}\text { Certidão de óbito } \\
\text { do cônj uge } \\
\text { falecido, da } \\
\text { anulação do } \\
\text { casamento } \\
\text { anterior ou do } \\
\text { registro da } \\
\text { sentença de } \\
\text { divórcio }\end{array}$ & \\
\hline $\begin{array}{l}\text { Article } 15- \\
\text { Art. } 262-1 \\
\text { J ugement de } \\
\text { divorce }\end{array}$ & $\begin{array}{l}\text { Le jugement de divorce } \\
\text { prend effet dans les } \\
\text { rapports entre les } \\
\text { époux, en ce qui } \\
\text { concerne leurs biens. }\end{array}$ & $\begin{array}{l}\text { Art. } 180-\mathrm{V} \\
\text { Sentença de } \\
\text { divórcio }\end{array}$ & $\begin{array}{l}\text { Certidão de óbito } \\
\text { do cônj uge } \\
\text { falecido, da } \\
\text { anulação do } \\
\text { casamento } \\
\text { anterior ou do } \\
\text { registro da } \\
\text { sentença de } \\
\text { divórcio }\end{array}$ & \\
\hline $\begin{array}{l}\text { Article 11- II } \\
\text { 20: } \\
\text { Principe du } \\
\text { divorce }\end{array}$ & $\begin{array}{c}\text { Le juge cherche à } \\
\text { concilier les époux tant } \\
\text { sur le principe du } \\
\text { divorce que sur ses } \\
\text { conséquences }\end{array}$ & & $\begin{array}{l}\text { Art } 46 \text { - Seja qual } \\
\text { for a causa da } \\
\text { separação } \\
\text { judicial, e o modo } \\
\text { como esta se faça, } \\
\text { é permitido aos } \\
\text { cônjuges } \\
\text { restabelecer a } \\
\text { todo o tempo a } \\
\text { sociedade } \\
\text { conjugal }\end{array}$ & $\begin{array}{l}\text { Causa do } \\
\text { divórcio }\end{array}$ \\
\hline $\begin{array}{l}\text { Article } 12 \text { - III: } \\
\text { Art. } 255 \S 60 \\
\text { Pension } \\
\text { alimentaire }\end{array}$ & $\begin{array}{c}\text { Fixer la pension } \\
\text { alimentaire et la } \\
\text { provision pour frais } \\
\text { d'instance que l'un des } \\
\text { époux devra verser à son } \\
\text { conjoint, désigner celui } \\
\text { ou ceux des époux qui } \\
\text { devront assurer le } \\
\text { règlement provisoire de } \\
\text { tout ou partie des } \\
\text { dettes. }\end{array}$ & $\begin{array}{l}\text { Seção IV Art. } \\
21 \\
\text { Pensão } \\
\text { alimentícia }\end{array}$ & $\begin{array}{l}\text { Para assegurar o } \\
\text { pagamento da } \\
\text { pensão } \\
\text { alimentícia, o juiz } \\
\text { poderá determinar } \\
\text { a constituição de } \\
\text { garantia real ou } \\
\text { fidej ussória. }\end{array}$ & \\
\hline $\begin{array}{l}\text { Article } 5 \text { - III: } \\
\text { Art. } 246\end{array}$ & $\begin{array}{l}\text { Si une demande pour } \\
\text { altération définitive du }\end{array}$ & & & $\begin{array}{l}\text { Divórcio por } \\
\text { alteração }\end{array}$ \\
\hline
\end{tabular}


ALVES, M. V. - Uma reflexão sobre o uso das modalidades de tradução no contexto jurídico

\begin{tabular}{|c|c|c|c|c|}
\hline $\begin{array}{l}\text { Divorce pour } \\
\text { altération } \\
\text { définitive du } \\
\text { lien conjugal }\end{array}$ & $\begin{array}{c}\text { lien conjugal et une } \\
\text { demande pour faute sont } \\
\text { concurremment } \\
\text { présentées, le juge } \\
\text { examine en premier lieu } \\
\text { la demande pour faute. } \\
\text { S'il rejette celle-ci, le } \\
\text { juge statue sur la } \\
\text { demande en divorce } \\
\text { pour altération } \\
\text { définitive du lien } \\
\text { conjugal }\end{array}$ & --- & $\begin{array}{l}\text { Art. 40: No caso } \\
\text { de separação de } \\
\text { fato, e desde que } \\
\text { completados } 2 \\
\text { (dois) anos } \\
\text { consecutivos, } \\
\text { poderá ser } \\
\text { promovida ação de } \\
\text { divórcio, na qual } \\
\text { deverá ser } \\
\text { comprovado }\end{array}$ & $\begin{array}{c}\text { definitiva do } \\
\text { vínculo } \\
\text { conjugal }\end{array}$ \\
\hline $\begin{array}{l}\text { Article } 7 \text { - II: } \\
\text { Art. 247-2 } \\
\text { Divorce pour } \\
\text { faute }\end{array}$ & $\begin{array}{l}\text { Si, dans le cadre d'une } \\
\text { instance introduite pour } \\
\text { altération définitive du } \\
\text { lien conjugal, le } \\
\text { défendeur demande } \\
\text { reconventionnellement } \\
\text { le divorce pour faute, le } \\
\text { demandeur peut } \\
\text { invoquer les fautes de } \\
\text { son conjoint pour } \\
\text { modifier le fondement } \\
\text { de sa demande }\end{array}$ & --.-- & $-\cdots-$ & $\begin{array}{c}\text { Divórcio por } \\
\text { culpa }\end{array}$ \\
\hline
\end{tabular}

Os termos foram classificados na modalidade palavra por palavra por motivos evidentes, porém alguns devem ser evidenciados, como o caso de prononcer le divorce $\mathrm{x}$ "decretar o divórcio". Esse caso foi classificado como palavra por palavra apesar de "decretar" não ser uma tradução literal de prononcer. No entanto, no contexto jurídico, a tradução de prononcer le divorce como "decretar o divórcio" é evidentemente literal, pois na linguagem jurídica brasileira o termo usado para expressar o mesmo significado do contexto francês é decretar e não pronunciar um divórcio.

Outros casos que devem ser mencionados também são os de instance en divorce $x$ sentença de divórcio e jugement de divorce $x$ sentença de divórcio. Nesse caso, dois termos diferentes do francês foram comparados com o mesmo termo no português. Isso ocorreu pelo mesmo motivo explicado no caso de prononcer le divorce. Apesar de os termos em francês serem diferentes, eles 
ALVES, M. V. - Uma reflexão sobre o uso das modalidades de tradução no contexto jurídico

possuem o mesmo significado no português e, assim, os dois termos diferentes do francês e seus respectivos termos iguais no português devem ser classificados na modalidade palavra por palavra. 0 mesmo ocorre também com o termo principe du divorce, cujo equivalente na lei brasileira seria "causa do divórcio", apesar de a palavra "causa" não ser a tradução literal de principe.

$\mathrm{Na}$ tabela, o termo divorce pour altération définitive du lien conjugal apresenta, na coluna referente ao contexto em português, um trecho da lei brasileira explicando o que seria a separação de fato. Em um primeiro momento, os termos foram comparados como equivalentes, entretanto, os termos "separação" e "divórcio" não são equivalentes, pois a separação permite a reconstrução do vínculo matrimonial, diferentemente do divórcio. Assim, divorce pour altération définitive du lien conjugal e "separação de fato" podem ser comparados apenas em relação ao tempo de separação do casal. 0 "divórcio por alteração definitiva do vínculo conjugal", da lei francesa, se dá após dois anos da separação do casal, ou seja, dois anos de vivência separada, assim como a separação de fato, que ocorre quando o casal vive separado há dois anos consecutivos. Assim, mesmo com a existência de semelhanças entre os termos, eles não puderam ser comparados devido a diferença entre "divórcio" e "separação" e, por isso, foi sugerida uma tradução literal para divorce pour altération définitive du lien conjugal. Vale ressaltar também que não é mais necessário tal prazo de separação, na lei brasileira, para obtenção do divórcio, visto que os cônjuges agora podem entrar com um pedido de divórcio direto ${ }^{4}$, porém ainda existem processos mais antigos que pedem a conversão da separação em divórcio.

Por fim, outra ocorrência que deve ser mencionada é pension alimentaire x "pensão alimentícia". Os termos foram classificados como equivalentes apesar de não serem totalmente comparáveis. A pensão alimentícia francesa ${ }^{5}$, pode ser solicitada para os filhos advindos da união, para um dos cônjuges ou outros familiares como sogro ou sogra, cunhado ou cunhada,

\footnotetext{
${ }^{4}$ De acordo com a Emenda Constitucional no 66

${ }^{5}$ De acordo com o site http:// vosdroits. service-public. fr/ particuliers/ F1728.xhtml
} 
ALVES, M. V. - Uma reflexão sobre o uso das modalidades de tradução no contexto jurídico

etc., diferentemente da pensão alimentícia da lei brasileira, que é exclusivamente para os filhos advindos da união e/ ou um dos cônjuges. Apesar dessa diferença, em ambos os casos, a pensão alimentícia é um valor fixo determinado pelo juiz a ser pago pelo cônjuge responsável pela separação judicial.

\section{Considerações finais}

Considerando os resultados apresentados e analisados acima, pode-se confirmar a preponderância de um determinado eixo de tradução neste estudo de caso, que é o da literalidade, apesar de ser esperado que em contextos jurídicos exista mais equivalências do que literalidades, pois, como já afirmado, os textos jurídicos são marcados culturalmente, havendo poucas equivalências plenas dos termos jurídicos entre diferentes países.

Apesar de mais de $70 \%$ dos termos terem sido classificados no eixo da literalidade, contrariando a hipótese inicial de que o eixo da equivalência seria predominante, é possível observar que até mesmo no eixo da literalidade podese encontrar marcadores culturais, como no caso do termo prononcer le divorce, que, apesar de seu equivalente em português não ser exatamente literal, pode ser sim classificado como tradução palavra por palavra, já que é o termo usado no contexto jurídico, pois dizemos que um divórcio foi decretado e não pronunciado. Este e outros exemplos de termos classificados como literais que, na verdade, também são equivalentes, confirmam que o contexto jurídico realmente apresenta muitos marcadores culturais, e essas diferenças culturais são tantas que a equivalência pode ser condiserada uma literalidade, pois, como já afirmado, se o termo prononcer le divorce fosse traduzido por "pronunciar o divórcio", ele não seria compreendido pelo leitor final de uma tradução juramentada, por exemplo.

Além disso, a maioria das ocorrências analisadas neste artigo estão inseridas no eixo da literalidade talvez pelo fato de as línguas portuguesa e 
ALVES, M. V. - Uma reflexão sobre o uso das modalidades de tradução no contexto jurídico

francesa serem muito próximas entre si, no entanto, isso só poderia ser confirmado a partir de uma análise extensa de uma quantidade bem maior de termos, ou seja, um trabalho que poderá ser desenvolvido futuramente.

\section{Referências bibliográficas}

AUBERT, F. H. Em busca das refrações na literatura brasileira traduzida - revendo a ferramenta de análise. In: Revista Literatura e Sociedade. 09 ed. São Paulo: 2006, pp. 60-69.

Introdução à metodologia da pesquisa terminológica bilíngue. In: Citrat. (Org.). Cadernos de Terminologia. 02 ed. São Paulo: 2001 Problemas e urgências da interrelação terminologia/tradução. Alfa, São Paulo, 36: 81-86, 1992.

BoBsIN, D.R.O. O divórcio após a Emenda Constitucional no66. Disponível em: বttp:// www. ambito-

juridico.com. br/ site/? ?_link=revista_artigos_leitura\&artigo_id=12235>. Acesso em 28/ 05/ 2013.

BrasIL. LEI № 6.515, DE 26 DE DEZEMBRO DE 1977. Disponível em: বhttp:// www. planalto.gov.br/ccivil_03/leis//6515.htm>. Acesso em 28/05/ 2013.

France. Loi no 2004-439 du 26 mai 2004 - art. 229. Disponível em: বhttp:/ / www. legifrance. gouv. fr/ affichCodeArticle. do; jsessionid=FBE17A64FB 1A85FF0B0E2A51AB7330F0.tpdj 014v_1?idArticle=LEGIARTI000006422958\&cidTe $x t e=L E G I T E X T 000006070721 \&$ dateTexte $=20050211>$. Acesso em 28/ 05/ 2013.

REDE JUDICIÁRIA EUROPEIA. Divórcio na França. Disponível em: বttp:// ec. europa. eu/civiljustice/ divorce/ divorce_fra_pt.htm. Acesso em 28/05/2013.

Zavaglia, A.; Poppl, C. Aspectos culturais da tradução juramentada. In: Citrat. (Org. ). Cadernos de Terminologia. 05 ed. São Paulo: 2012, v. 05, pp. 54-83. 
ALVES, M. V. - Uma reflexão sobre o uso das modalidades de tradução no contexto jurídico

\section{Anexos}

ANEXO I

LOI $n^{\circ}$ 2004-439 du 26 mai 2004 relative au divorce (1)

NOR: J USX0300062L

ELI: Non disponible

L'Assemblée nationale et le Sénat ont adopté,

Le Président de la République promulgue la loi dont la teneur suit :

\section{- TITRE Ier : DISPOSITIONS MODIFIANT LE CODE CIVIL}

\section{Article 1}

L'article 229 du code civil est ainsi rédigé :

«Art. 229. - Le divorce peut être prononcé en cas :

«- soit de consentement mutuel ;

«- soit d'acceptation du principe de la rupture du mariage ;

«- soit d'altération définitive du lien conjugal ;

« - soit de faute. »

- Chapitre ler : Des cas de divorce

Article 2

I. - Dans la section 1 du chapitre ler du titre VI du livre ler du code civil, les divisions: « Paragraphe ler » et «Paragraphe 2 » et leurs intitulés sont supprimés.

II. - Cette section comprend deux articles 230 et 232 ainsi rédigés :

«Art. 230. - Le divorce peut être demandé conjointement par les époux Iorsqu'ils s'entendent sur la rupture du mariage et ses effets en soumettant à l'approbation du juge une convention réglant les conséquences du divorce.

«Art. 232. - Le juge homologue la convention et prononce le divorce s'il a acquis la conviction que la volonté de chacun des époux est réelle et que leur consentement est libre et éclairé.

« II peut refuser l'homologation et ne pas prononcer le divorce s'il constate que la convention préserve insuffisamment les intérêts des enfants ou de l'un des époux. »

\section{Article 3}


ALVES, M. V. - Uma reflexão sobre o uso das modalidades de tradução no contexto jurídico

I. - L'intitulé de la section 2 du chapitre ler du titre VI du livre ler du code civil est ainsi rédigé : «Du divorce accepté 》.

II. - Cette section comprend deux articles 233 et 234 ainsi rédigés :

«Art. 233. - Le divorce peut être demandé par l'un ou l'autre des époux ou par les deux lorsqu'ils acceptent le principe de la rupture du mariage sans considération des faits à I'origine de celle-ci.

«Cette acceptation n'est pas susceptible de rétractation, même par la voie de l'appel. «Art. 234. - S'il a acquis la conviction que chacun des époux a donné librement son accord, le juge prononce le divorce et statue sur ses conséquences. »

\section{Article 4}

I. - Avant I'article 237 du code civil, il est inséré une section 3 intitulée : « Du divorce pour altération définitive du lien conjugal $»$.

II. - Cette section comprend deux articles 237 et 238 ainsi rédigés:

«Art. 237. - Le divorce peut être demandé par l'un des époux lorsque le lien conjugal est définitivement altéré.

«Art. 238. - L'altération définitive du lien conjugal résulte de la cessation de la communauté de vie entre les époux, lorsqu'ils vivent séparés depuis deux ans lors de l'assignation en divorce.

« Nonobstant ces dispositions, le divorce est prononcé pour altération définitive du lien conjugal dans le cas prévu au second alinéa de l'article 246, dès lors que la demande présentée sur ce fondement est formée à titre reconventionnel. »

\section{Article 5}

I. - Après l'article 238 du code civil, il est inséré une section 4 intitulée : « Du divorce pour faute », qui comprend les articles 242, 244, 245, 245-1, tel qu'il résulte de l'article 6 , et 246 .

II. - L'article 242 du même code est ainsi rédigé :

«Art. 242. - Le divorce peut être demandé par l'un des époux lorsque des faits constitutifs d'une violation grave ou renouvelée des devoirs et obligations du mariage sont imputables à son conjoint et rendent intolérable le maintien de la vie commune. » III. - L'article 246 du même code est ainsi rédigé :

«Art. 246. - Si une demande pour altération définitive du lien conjugal et une demande pour faute sont concurremment présentées, le juge examine en premier lieu la demande pour faute.

«S'il rejette celle-ci, le juge statue sur la demande en divorce pour altération définitive du lien conjugal. »

\section{Article 6}


ALVES, M. V. - Uma reflexão sobre o uso das modalidades de tradução no contexto jurídico

Les articles 247, 248-1, 251, 252, 252-1, 252-2, 252-3, le second alinéa de l'article 271, les articles 275-1, 276-2, 280 et 1450 du code civil deviennent respectivement les articles 228, 245-1, 252, 252-1, 252-2, 252-3, 252-4, 272, 275, 280-2, 281 et 265-2.

Article 7

I. - Après l'article 246 du code civil, il est inséré une section 5 intitulée : « Des modifications du fondement d'une demande en divorce ».

II. - Cette section comprend trois articles 247, 247-1 et 247-2 ainsi rédigés :

«Art. 247. - Les époux peuvent, à tout moment de la procédure, demander au juge de constater leur accord pour voir prononcer leur divorce par consentement mutuel en lui présentant une convention réglant les conséquences de celui-ci.

«Art. 247-1. - Les époux peuvent également, à tout moment de la procédure, lorsque le divorce aura été demandé pour altération définitive du lien conjugal ou pour faute, demander au juge de constater leur accord pour voir prononcer le divorce pour acceptation du principe de la rupture du mariage.

«Art. 247-2. - Si, dans le cadre d'une instance introduite pour altération définitive du lien conjugal, le défendeur demande reconventionnellement le divorce pour faute, le demandeur peut invoquer les fautes de son conjoint pour modifier le fondement de sa demande. »

\section{- Chapitre II : De la procédure du divorce}

Article 8

Les articles 249, 249-3 et 249-4 du code civil sont ainsi modifiés:

$1^{\circ}$ Le premier alinéa de l'article 249 est ainsi rédigé :

«Si une demande en divorce doit être formée au nom d'un majeur en tutelle, elle est présentée par le tuteur, avec l'autorisation du conseil de famille s'il a été institué ou du juge des tutelles. Elle est formée après avis du médecin traitant et, dans la mesure du possible, après audition de l'intéressé, selon le cas, par le conseil de famille ou le juge. » i

$2^{\circ}$ L'article 249-3 est complété par une phrase ainsi rédigée :

« Toutefois, le juge peut prendre les mesures provisoires prévues aux articles 254 et 255 et les mesures urgentes prévues à l'article 257. »;

$3^{\circ} \mathrm{A}$ l'article 249-4, après les mots : " par consentement mutuel », sont insérés les mots : " ou pour acceptation du principe de la rupture du mariage ».

\section{Article 9}

I. - L'intitulé de la section 2 du chapitre II du titre VI du livre ler du code civil est ainsi 
ALVES, M. V. - Uma reflexão sobre o uso das modalidades de tradução no contexto jurídico

rédigé : «De la procédure applicable au divorce par consentement mutuel 》. II. - Cette section comprend quatre articles 250, 250-1, 250-2 et 250-3 ainsi rédigés : «Art. 250. - La demande en divorce est présentée par les avocats respectifs des parties ou par un avocat choisi d'un commun accord.

"Le juge examine la demande avec chacun des époux, puis les réunit. II appelle ensuite le ou les avocats.

«Art. 250-1. - Lorsque les conditions prévues à l'article 232 sont réunies, le juge homologue la convention réglant les conséquences du divorce et, par la même décision, prononce celui-ci.

«Art. 250-2. - En cas de refus d'homologation de la convention, le juge peut cependant homologuer les mesures provisoires au sens des articles 254 et 255 que les parties s'accordent à prendre jusqu'à la date à laquelle le jugement de divorce passe en force de chose jugée, sous réserve qu'elles soient conformes à l'intérêt du ou des enfants. « Une nouvelle convention peut alors être présentée par les époux dans un délai maximum de six mois.

«Art. 250-3. - A défaut de présentation d'une nouvelle convention dans le délai fixé à I'article 250-2 ou si le juge refuse une nouvelle fois I'homologation, la demande en divorce est caduque. »

\section{Article 10}

I. - L'intitulé de la section 3 du chapitre II du titre VI du livre ler du code civil est ainsi rédigé : « De la procédure applicable aux autres cas de divorce ».

Cette section comprend les articles 251 à 259-3.

II. - Il est inséré dans cette section un paragraphe ler intitulé : «De la requête initiale », qui comprend l'article 251 ainsi rédigé :

«Art. 251. - L'époux qui forme une demande en divorce présente, par avocat, une requête au juge, sans indiquer les motifs du divorce. »

\section{Article 11}

I. - Après l'article 251 du code civil, il est inséré un paragraphe 2 intitulé : « De la conciliation », qui comprend les articles 252, 252-1, 252-2, 252-3, 252-4 et 253. II. - L'article 252 du même code, tel qu'il résulte de l'article 6, est ainsi modifié : $1^{\circ}$ Au premier alinéa, les mots: "Quand le divorce est demandé pour rupture de la vie commune ou pour faute, » sont supprimés ;

$2^{\circ}$ Le deuxième alinéa est ainsi rédigé :

«Le juge cherche à concilier les époux tant sur le principe du divorce que sur ses conséquences. »

III. - L'article 252-1 du même code, tel qu'il résulte de l'article 6, est ainsi modifié :

$1^{\circ}$ Le deuxième alinéa est ainsi rédigé :

«Les avocats sont ensuite appelés à assister et à participer à l'entretien. 》 ;

$2^{\circ}$ Le troisième alinéa est ainsi rédigé : 
ALVES, M. V. - Uma reflexão sobre o uso das modalidades de tradução no contexto jurídico

« Dans le cas où l'époux qui n'a pas formé la demande ne se présente pas à l'audience ou se trouve hors d'état de manifester sa volonté, le juge s'entretient avec l'autre conjoint et I'invite à la réflexion. »

IV. - L'article 252-3 du même code, tel qu'il résulte de l'article 6 , est ainsi rédigé :

«Art. 252-3. - Lorsque le juge constate que le demandeur maintient sa demande, il incite les époux à régler les conséquences du divorce à l'amiable.

« II leur demande de présenter pour l'audience de jugement un projet de règlement des effets du divorce. A cet effet, il peut prendre les mesures provisoires prévues à l'article 255. »

V. - L'article 253 du même code est ainsi rédigé :

«Art. 253. - Les époux ne peuvent accepter le principe de la rupture du mariage et le prononcé du divorce sur le fondement de l'article 233 que s'ils sont chacun assistés par un avocat. »

\section{Article 12}

I. - Après l'article 253 du code civil, il est inséré un paragraphe 3 intitulé : « Des mesures provisoires », qui comprend les articles 254, 255, 256 et 257.

II. - L'article 254 du même code est ainsi rédigé :

«Art. 254. - Lors de l'audience prévue à l'article 252, le juge prescrit, en considération des accords éventuels des époux, les mesures nécessaires pour assurer leur existence et celle des enfants jusqu'à la date à laquelle le jugement passe en force de chose jugée. » III. - L'article 255 du même code est ainsi rédigé :

«Art. 255. - Le juge peut notamment :

« $1^{\circ}$ Proposer aux époux une mesure de médiation et, après avoir recueilli leur accord, désigner un médiateur familial pour y procéder ;

« $2^{\circ}$ Enjoindre aux époux de rencontrer un médiateur familial qui les informera sur l'objet et le déroulement de la médiation;

« $3^{\circ}$ Statuer sur les modalités de la résidence séparée des époux;

« $4^{\circ}$ Attribuer à l'un d'eux la jouissance du logement et du mobilier du ménage ou partager entre eux cette jouissance, en précisant son caractère gratuit ou non et, le cas échéant, en constatant l'accord des époux sur le montant d'une indemnité d'occupation ; « $5^{\circ}$ Ordonner la remise des vêtements et obj ets personnels ;

« $6^{\circ}$ Fixer la pension alimentaire et la provision pour frais d'instance que l'un des époux devra verser à son conjoint, désigner celui ou ceux des époux qui devront assurer le règlement provisoire de tout ou partie des dettes ;

« $7^{\circ}$ Accorder à l'un des époux des provisions à valoir sur ses droits dans la liquidation du régime matrimonial si la situation le rend nécessaire ;

" $8^{\circ}$ Statuer sur l'attribution de la jouissance ou de la gestion des biens communs ou indivis autres que ceux visés au $4^{\circ}$, sous réserve des droits de chacun des époux dans la liquidation du régime matrimonial ;

« $9^{\circ}$ Désigner tout professionnel qualifié en vue de dresser un inventaire estimatif ou de faire des propositions quant au règlement des intérêts pécuniaires des époux ; 
ALVES, M. V. - Uma reflexão sobre o uso das modalidades de tradução no contexto jurídico

« $10^{\circ}$ Désigner un notaire en vue d'élaborer un projet de liquidation du régime matrimonial et de formation des lots à partager. »

\section{Article 13}

I. - Après l'article 257 du code civil, il est inséré un paragraphe 4 intitulé : «De I'introduction de l'instance en divorce », qui comprend les articles 257-1, 257-2 et 258. II. - Les articles 257-1 et 257-2 du même code sont ainsi rédigés:

«Art. 257-1. - Après I'ordonnance de non-conciliation, un époux peut introduire l'instance ou former une demande reconventionnelle pour acceptation du principe de la rupture du mariage, pour altération définitive du lien conjugal ou pour faute.

«Toutefois, lorsqu'à l'audience de conciliation les époux ont déclaré accepter le principe de la rupture du mariage et le prononcé du divorce sur le fondement de l'article 233, l'instance ne peut être engagée que sur ce même fondement.

«Art. 257-2. - A peine d'irrecevabilité, la demande introductive d'instance comporte une proposition de règlement des intérêts pécuniaires et patrimoniaux des époux. »

\section{Article 14}

I. - La section 4 du chapitre II du titre VI du livre ler du code civil devient le paragraphe 5 de la section 3 du même chapitre.

II. - L'article 259 du même code est complété par une phrase ainsi rédigée :

«Toutefois, les descendants ne peuvent jamais être entendus sur les griefs invoqués par les époux. »

III. - L'article 259-1 du même code est ainsi rédigé :

«Art. 259-1. - Un époux ne peut verser aux débats un élément de preuve qu'il aurait obtenu par violence ou fraude. »

IV. - Au premier alinéa de l'article 259-3 du même codé, les mots : « désignés par lui » sont remplacés par les mots : « et autres personnes désignés par lui en application des $9^{\circ}$ et $10^{\circ}$ de l'article 255 , ».

V. - A l'article 272 du même code, tel qu'il résulte de l'article 6, les mots : « dans la convention visée à l'article 278 » sont supprimés.

\section{- Chapitre III : Des conséquences du divorce}

\section{Article 15}

L'article 262-1 du code civil est ainsi rédigé :

«Art. 262-1. - Le jugement de divorce prend effet dans les rapports entre les époux, en ce qui concerne leurs biens :

«- lorsqu'il est prononcé par consentement mutuel, à la date de I'homologation de la convention réglant l'ensemble des conséquences du divorce, à moins que celle-ci n'en 
ALVES, M. V. - Uma reflexão sobre o uso das modalidades de tradução no contexto jurídico

dispose autrement ;

«- Iorsqu'il est prononcé pour acceptation du principe de la rupture du mariage, pour altération définitive du lien conjugal ou pour faute, à la date de l'ordonnance de nonconciliation.

«A la demande de l'un des époux, le juge peut fixer les effets du jugement à la date à laquelle ils ont cessé de cohabiter et de collaborer. Cette demande ne peut être formée qu'à l'occasion de l'action en divorce. La jouissance du logement conjugal par un seul des époux conserve un caractère gratuit jusqu'à I'ordonnance de non-conciliation, sauf décision contraire du juge. »

\section{Article 16}

Le paragraphe 1 de la section 2 du chapitre III du titre VI du livre ler du code civil comprend, outre les articles 263 et 265-2 tel qu'il résulte de l'article 6, trois articles 264, 265 et 265-1 ainsi rédigés :

«Art. 264. - A la suite du divorce, chacun des époux perd l'usage du nom de son conjoint. "L'un des époux peut néanmoins conserver l'usage du nom de l'autre, soit avec l'accord de celui-ci, soit avec l'autorisation du juge, s'il justifie d'un intérêt particulier pour lui ou pour les enfants.

«Art. 265. - Le divorce est sans incidence sur les avantages matrimoniaux qui prennent effet au cours du mariage et sur les donations de biens présents quelle que soit leur forme.

«Le divorce emporte révocation de plein droit des avantages matrimoniaux qui ne prennent effet qu'à la dissolution du régime matrimonial ou au décès de l'un des époux et des dispositions à cause de mort, accordés par un époux envers son conjoint par contrat de mariage ou pendant l'union, sauf volonté contraire de l'époux qui les a consentis. Cette volonté est constatée par le juge au moment du prononcé du divorce et rend irrévocables l'avantage ou la disposition maintenus.

«Art. 265-1. - Le divorce est sans incidence sur les droits que l'un ou l'autre des époux tient de la loi ou des conventions passées avec des tiers. »

\section{Article 17}

I. - Le paragraphe 2 de la section 2 du chapitre III du titre VI du livre ler du code civil est intitulé : «Des conséquences propres aux divorces autres que par consentement mutuel $\gg$.

II. - II comprend quatre articles 266, 267, 267-1 et 268 ainsi rédigés:

« Art. 266. - Sans préjudice de l'application de l'article 270, des dommages et intérêts peuvent être accordés à un époux en réparation des conséquences d'une particulière gravité qu'il subit du fait de la dissolution du mariage soit lorsqu'il était défendeur à un divorce prononcé pour altération définitive du lien conjugal et qu'il n'avait lui-même formé aucune demande en divorce, soit lorsque le divorce est prononcé aux torts exclusifs de son conjoint. 
ALVES, M. V. - Uma reflexão sobre o uso das modalidades de tradução no contexto jurídico

«Cette demande ne peut être formée qu'à l'occasion de l'action en divorce.

«Art. 267. - A défaut d'un règlement conventionnel par les époux, le juge, en prononçant le divorce, ordonne la liquidation et le partage de leurs intérêts patrimoniaux.

«II statue sur les demandes de maintien dans l'indivision ou d'attribution préférentielle.

« II peut aussi accorder à I'un des époux ou aux deux une avance sur sa part de communauté ou de biens indivis.

«Si le projet de liquidation du régime matrimonial établi par le notaire désigné sur le fondement du $10^{\circ}$ de l'article 255 contient des informations suffisantes, le juge, à la demande de l'un ou l'autre des époux, statue sur les désaccords persistant entre eux. «Art. 267-1. - Si les opérations de liquidation et de partage ne sont pas achevées dans le délai d'un an après que le jugement de divorce est passé en force de chose jugée, le notaire transmet au tribunal un procès-verbal de difficultés reprenant les déclarations respectives des parties.

«Au vu de celui-ci, le tribunal peut accorder un délai supplémentaire d'une durée maximale de six mois.

« Si, à l'expiration de ce délai, les opérations ne sont touj ours pas achevées, le notaire en informe le tribunal. Il établit, si les changements intervenus le rendent nécessaire, un nouveau procès-verbal.

«Le tribunal statue sur les contestations subsistant entre les parties et les renvoie devant le notaire afin d'établir l'état liquidatif.

«Art. 268. - Les époux peuvent, pendant l'instance, soumettre à l'homologation du juge des conventions réglant tout ou partie des conséquences du divorce.

«Le juge, après avoir vérifié que les intérêts de chacun des époux et des enfants sont préservés, homologue les conventions en prononçant le divorce. »

\section{Article 18}

I. - L'article 270 du code civil est ainsi rédigé :

«Art. 270. - Le divorce met fin au devoir de secours entre époux.

"L'un des époux peut être tenu de verser à l'autre une prestation destinée à compenser, autant qu'il est possible, la disparité que la rupture du mariage crée dans les conditions de vie respectives. Cette prestation a un caractère forfaitaire. Elle prend la forme d'un capital dont le montant est fixé par le juge.

«Toutefois, le juge peut refuser d'accorder une telle prestation si l'équité le commande, soit en considération des critères prévus à l'article 271, soit lorsque le divorce est prononcé aux torts exclusifs de l'époux qui demande le bénéfice de cette prestation, au regard des circonstances particulières de la rupture. »

II. - L'article 271 du même code est complété par huit alinéas ainsi rédigés :

«A cet effet, le juge prend en considération notamment :

«- la durée du mariage ;

« - l'âge et l'état de santé des époux ;

«- leur qualification et leur situation professionnelles;

" - les conséquences des choix professionnels faits par l'un des époux pendant la vie

commune pour l'éducation des enfants et du temps qu'il faudra encore y consacrer ou 
ALVES, M. V. - Uma reflexão sobre o uso das modalidades de tradução no contexto jurídico

pour favoriser la carrière de son conjoint au détriment de la sienne ;

«- le patrimoine estimé ou prévisible des époux, tant en capital qu'en revenu, après la

liquidation du régime matrimonial ;

«- leurs droits existants et prévisibles ;

«- leur situation respective en matière de pensions de retraite. »

III. - L'article 274 du même code est ainsi rédigé :

«Art. 274. - Le juge décide des modalités selon lesquelles s'exécutera la prestation compensatoire en capital parmi les formes suivantes:

« $1^{\circ}$ Versement d'une somme d'argent, le prononcé du divorce pouvant être subordonné à la constitution des garanties prévues à l'article 277 ;

« $2^{\circ}$ Attribution de biens en propriété ou d'un droit temporaire ou viager d'usage, d'habitation ou d'usufruit, le jugement opérant cession forcée en faveur du créancier.

Toutefois, l'accord de l'époux débiteur est exigé pour l'attribution en propriété de biens qu'il a reçus par succession ou donation. »

IV. - L'article 275 du même code, tel qu'il résulte de l'article 6, est ainsi modifié :

$1^{\circ}$ Au premier alinéa, la référence : « 275 » est remplacée par la référence : « 274 », et les mots : «mensuels ou annuels » sont remplacés par le mot : «périodiques »;

$2^{\circ}$ Au deuxième alinéa, le mot : «notable » est remplacé par le mot : «important »;

$3^{\circ}$ Le troisième alinéa est supprimé ;

$4^{\circ}$ L'avant-dernier alinéa est ainsi rédigé :

"Le débiteur peut se libérer à tout moment du solde du capital indexé. »;

$5^{\circ}$ Le dernier alinéa est complété par le mot : «indexé ».

V. - L'article 275-1 du même code est ainsi rétabli :

«Art. 275-1. - Les modalités de versement prévues au premier alinéa de l'article 275 ne sont pas exclusives du versement d'une partie du capital dans les formes prévues par l'article 274. »

VI. - L'article 276 du même code est ainsi rédigé :

«Art. 276. - A titre exceptionnel, le juge peut, par décision spécialement motivée, lorsque l'âge ou l'état de santé du créancier ne lui permet pas de subvenir à ses besoins, fixer la prestation compensatoire sous forme de rente viagère. II prend en considération les éléments d'appréciation prévus à l'article 271.

«Le montant de la rente peut être minoré, lorsque les circonstances l'imposent, par I'attribution d'une fraction en capital parmi les formes prévues à l'article 274. » VII. - L'article 276-4 du même code est ainsi modifié :

$1^{\circ}$ Les deux premiers alinéas sont remplacés par un alinéa ainsi rédigé :

"Le débiteur d'une prestation compensatoire sous forme de rente peut, à tout moment, saisir le juge d'une demande de substitution d'un capital à tout ou partie de la rente. La substitution s'effectue selon des modalités fixées par décret en Conseil d'Etat. » ; $2^{\circ}$ II est complété par un alinéa ainsi rédigé :

«Les modalités d'exécution prévues aux articles 274, 275 et 275-1 sont applicables. Le refus du juge de substituer un capital à tout ou partie de la rente doit être spécialement motivé. »

VIII. - Après l'article 279 du même code, il est inséré un article 279-1 ainsi rédigé :

«Art. 279-1. - Lorsqu'en application de l'article 268, les époux soumettent à

I 'homologation du juge une convention relative à la prestation compensatoire, les

TradTerm, São Paulo, v. 24, Dezembro/2014, pp. 83-125

www. usp. br/tradterm

http:// www. revistas. usp. br/ tradterm/ index 
ALVES, M. V. - Uma reflexão sobre o uso das modalidades de tradução no contexto jurídico

dispositions des articles 278 et 279 sont applicables. »

IX. - L'article 280 du même code est ainsi rédigé :

«Art. 280. - A la mort de l'époux débiteur, le paiement de la prestation compensatoire, quelle que soit sa forme, est prélevé sur la succession. Le paiement est supporté par tous les héritiers, qui n'y sont pas tenus personnellement, dans la limite de l'actif successoral et, en cas d'insuffisance, par tous les légataires particuliers, proportionnellement à leur émolument, sous réserve de l'application de l'article 927.

«Lorsque la prestation compensatoire a été fixée sous forme d'un capital payable dans les conditions de l'article 275 , le solde de ce capital indexé devient immédiatement exigible. «Lorsqu'elle a été fixée sous forme de rente, il lui est substitué un capital immédiatement exigible. La substitution s'effectue selon des modalités fixées par décret en Conseil d'Etat. »

X. - L'article 280-1 du même code est ainsi rédigé :

«Art. 280-1. - Par dérogation à l'article 280, les héritiers peuvent décider ensemble de maintenir les formes et modalités de règlement de la prestation compensatoire qui incombaient à l'époux débiteur, en s'obligeant personnellement au paiement de cette prestation. A peine de nullité, l'accord est constaté par un acte notarié. II est opposable aux tiers à compter de sa notification à l'époux créancier lorsque celui-ci n'est pas intervenu à l'acte.

"Lorsque les modalités de règlement de la prestation compensatoire ont été maintenues, les actions prévues au deuxième alinéa de l'article 275 et aux articles 276-3 et 276-4, selon que la prestation compensatoire prend la forme d'un capital ou d'une rente temporaire ou viagère, sont ouvertes aux héritiers du débiteur. Ceux-ci peuvent également se libérer à tout moment du solde du capital indexé lorsque la prestation compensatoire prend la forme prévue au premier alinéa de l'article 275. »

\section{Article 19}

Le paragraphe 5 de la section 2 du chapitre III du titre VI du livre ler du code civil devient le paragraphe 4. Il comprend un article 285-1 ainsi rédigé :

«Art. 285-1. - Si le local servant de logement à la famille appartient en propre ou personnellement à l'un des époux, le juge peut le concéder à bail au conjoint qui exerce seul ou en commun l'autorité parentale sur un ou plusieurs de leurs enfants lorsque ceuxci résident habituellement dans ce logement et que leur intérêt le commande.

« Le juge fixe la durée du bail et peut le renouveler jusqu'à la majorité du plus jeune des enfants.

«Le juge peut résilier le bail si des circonstances nouvelles le justifient. »

\section{- Chapitre IV : De la séparation de corps}

\section{Article 20}

I. - Après la première phrase du premier alinéa de l'article 297 du code civil, il est inséré 
ALVES, M. V. - Uma reflexão sobre o uso das modalidades de tradução no contexto jurídico

une phrase ainsi rédigée :

«Toutefois, lorsque la demande principale en divorce est fondée sur l'altération définitive du lien conjugal, la demande reconventionnelle ne peut tendre qu'au divorce. » II. - Après l'article 297 du même code, il est inséré un article 297-1 ainsi rédigé :

«Art. 297-1. - Lorsqu'une demande en divorce et une demande en séparation de corps sont concurremment présentées, le juge examine en premier lieu la demande en divorce. II prononce celui-ci dès lors que les conditions en sont réunies. A défaut, il statue sur la demande en séparation de corps.

«Toutefois, lorsque ces demandes sont fondées sur la faute, le juge les examine simultanément et, s'il les accueille, prononce à l'égard des deux conjoints le divorce aux torts partagés. » III. - L'article 300 du même code est ainsi rédigé :

«Art. 300. - Chacun des époux séparés conserve I'usage du nom de l'autre. Toutefois, le jugement de séparation de corps ou un jugement postérieur peut, compte tenu des intérêts respectifs des époux, le leur interdire. »

IV. - Le troisième alinéa de l'article 303 du même code est remplacé par deux alinéas ainsi rédigés :

« Cette pension est soumise aux règles des obligations alimentaires.

"Toutefois, lorsque la consistance des biens de l'époux débiteur s'y prête, la pension alimentaire est remplacée, en tout ou partie, par la constitution d'un capital, selon les règles des articles 274 à $275-1,277$ et 281 . Si ce capital devient insuffisant pour couvrir les besoins du créancier, celui-ci peut demander un complément sous forme de pension alimentaire. »

\section{- Chapitre V : Des biens des époux}

\section{Article 21}

I. - L'article 1096 du code civil est ainsi rédigé :

«Art. 1096. - La donation de biens à venir faite entre époux pendant le mariage sera touj ours révocable.

«La donation de biens présents faite entre époux ne sera révocable que dans les conditions prévues par les articles 953 à 958.

"Les donations faites entre époux de biens présents ou de biens à venir ne sont pas révoquées par la survenance d'enfants. »

II. - La dernière phrase de l'article 1442 du même code est supprimée.

III. - Dans le premier alinéa de l'article 265-2 du même code, tel qu'il résulte de l'article

6 , les mots : « de la communauté » sont remplacés par les mots : « de leur régime matrimonial ».

IV. - Le second alinéa de l'article 265-2 du même code, tel qu'il résulte de l'article 6, est ainsi rédigé :

«Lorsque la liquidation porte sur des biens soumis à la publicité foncière, la convention doit être passée par acte notarié. »

V. - Dans le premier alinéa de l'article 1451 du même code, les mots : « ainsi passées »

TradTerm, São Paulo, v. 24, Dezembro/2014, pp. 83-125

www. usp. br/tradterm

http:// www. revistas. usp. br/ tradterm/ index 
ALVES, M. V. - Uma reflexão sobre o uso das modalidades de tradução no contexto jurídico

sont remplacés par les mots : «passées en application de l'article 265-2 ».

VI. - Dans l'article 1518 du même code, les mots : «à moins que les avantages

matrimoniaux n'aient été perdus de plein droit ou révoqués à la suite d'un jugement de divorce ou de séparation de corps, sans préjudice de l'application de l'article 268 » sont remplacés par les mots: « sous réserve de l'article 265 ».

VII. - L'article 1477 du même code est complété par un alinéa ainsi rédigé :

« De même, celui qui aurait dissimulé sciemment l'existence d'une dette commune doit I'assumer définitivement. »

\section{- Chapitre VI : Dispositions diverses}

\section{Article 22}

I. - Le troisième alinéa de l'article 220-1 du code civil est remplacé par deux alinéas ainsi rédigés :

«Lorsque les violences exercées par l'un des époux mettent en danger son conjoint, un ou plusieurs enfants, le juge peut statuer sur la résidence séparée des époux en précisant lequel des deux continuera à résider dans le logement conjugal. Sauf circonstances particulières, la jouissance de ce logement est attribuée au conjoint qui n'est pas l'auteur des violences. Le juge se prononce, s'il y a lieu, sur les modalités d'exercice de l'autorité parentale et sur la contribution aux charges du mariage. Les mesures prises sont caduques si, à l'expiration d'un délai de quatre mois à compter de leur prononcé, aucune requête en divorce ou en séparation de corps n'a été déposée.

«La durée des autres mesures prises en application du présent article doit être déterminée par le juge et ne saurait, prolongation éventuellement comprise, dépasser trois ans. »

II. - L'article 228 du même code, tel qu'il résulte de l'article 6, est inséré avant le chapitre ler du titre VI du livre ler du même code.

La première phrase du quatrième alinéa de cet article est ainsi rédigée :

« Il est également seul compétent, après le prononcé du divorce, quelle qu'en soit la cause, pour statuer sur les modalités de l'exercice de l'autorité parentale, sur la modification de la contribution à l'entretien et l'éducation des enfants et pour décider de confier ceux-ci à un tiers ainsi que sur la révision de la prestation compensatoire ou de ses modalités de paiement. »

III. - A l'article 245-1 du même code, tel qu'il résulte de l'article 6, les mots : « En cas de divorce pour faute, et » sont supprimés.

IV. - Au même article, les mots : « aux affaires familiales » sont supprimés.

V. - A l'article 256 du même code, les mots : « Les conséquences de la séparation pour les » sont remplacés par les mots : "Les mesures provisoires relatives aux».

VI. - Le premier alinéa de l'article 276-3 du même code est ainsi rédigé :

«La prestation compensatoire fixée sous forme de rente peut être révisée, suspendue ou supprimée en cas de changement important dans les ressources ou les besoins de l'une ou l'autre des parties. »

TradTerm, São Paulo, v. 24, Dezembro/ 2014, pp. 83-125

www. usp. br/tradterm

http:// www. revistas. usp. br/ tradterm/ index 
ALVES, M. V. - Uma reflexão sobre o uso das modalidades de tradução no contexto jurídico

VII. - A l'article 278 du même code, les mots : « demande conjointe » sont remplacés par les mots : « divorce par consentement mutuel».

VIII. - L'article 279 du même code est ainsi modifié :

$1^{\circ}$ Dans la première phrase du dernier alinéa, les mots : « et les besoins » sont remplacés par les mots: " ou les besoins de l'une ou l'autre »;

$2^{\circ}$ La dernière phrase du dernier alinéa est ainsi rédigée :

«Les dispositions prévues aux deuxième et troisième alinéas de l'article 275 ainsi qu'aux articles 276-3 et 276-4 sont également applicables, selon que la prestation compensatoire prend la forme d'un capital ou d'une rente temporaire ou viagère. » ;

$3^{\circ}$ Il est complété par un alinéa ainsi rédigé :

«Sauf disposition particulière de la convention, les articles 280 à 280-2 sont applicables.

$\gg$

IX. - L'article 280-2 du même code, tel qu'il résulte de l'article 6, est ainsi modifié :

$1^{\circ}$ La première phrase est supprimée ;

$2^{\circ}$ Les mots : « de la rente versée au créancier » sont remplacés par les mots : « du montant de la prestation compensatoire, lorsque celle-ci, au jour du décès, prenait la forme d'une rente » ;

$3^{\circ}$ Le début de la dernière phrase est ainsi rédigé : «Si les héritiers usent de la faculté prévue à l'article 280-1 et sauf décision... (le reste sans changement). » ;

$4^{\circ}$ Après les mots : « du juge », la fin de la dernière phrase est ainsi rédigée : «, une déduction du même montant continue à être opérée si le créancier perd son droit ou subit une variation de son droit à pension de réversion. »

X. - Dans la première phrase de l'article 281 du même code, tel qu'il résulte de l'article 6 , après le mot : « sont », sont insérés les mots : «, quelles que soient leurs modalités de versement, ».

XI. - A l'article 298 du même code, les mots : « au chapitre II » sont remplacés par les mots : «à l'article 228 ainsi qu'au chapitre II».

XII. - L'article 301 du même code est ainsi modifié :

$1^{\circ}$ La deuxième phrase est supprimée ;

$2^{\circ}$ Dans la dernière phrase, les mots : « sur demande conjointe » sont remplacés par les mots: «par consentement mutuel ».

XIII. - A l'article 306 du même code, le mot : «trois » est remplacé par le mot : « deux ». XIV. - A l'article 307 du même code, les mots : «par demande conjointe » et «sur demande conjointe » sont remplacés par les mots: " par consentement mutuel ». XV. - Dans le dernier alinéa de l'article 1397-1 du même code, la référence : « 1450 » est remplacée par la référence : « 265-2».

\section{Article 23}

I. - Sont abrogés :

$1^{\circ}$ Le chapitre VIII du titre $V$ du livre ler du code civil ;

$2^{\circ}$ Les articles 231, 235 et 236, 239 à 241, 243, 261 à 261-2, 264-1, 268-1 et 269, 273, 276-3 (troisième alinéa), 282 à 285, 297 (second alinéa), 309 et 1099 (second alinéa) du même code ; 
ALVES, M. V. - Uma reflexão sobre o uso das modalidades de tradução no contexto jurídico

$3^{\circ}$ Les articles 20 à 23 de la loi $n^{\circ} 2000-596$ du 30 juin 2000 relative à la prestation compensatoire en matière de divorce ;

$4^{\circ}$ L'article 52 de la loi n $93-22$ du 8 janvier 1993 modifiant le code civil relative à l'état civil, à la famille et aux droits de l'enfant et instituant le juge aux affaires familiales.

II. - L'intitulé et la division: « Section 3. - Du divorce pour faute » du chapitre ler du titre VI du livre ler du code civil sont abrogés.

\section{- TITRE II : DISPOSITIONS DIVERSES ET TRANSITOIRES}

\section{Article 24}

Dans le deuxième alinéa de l'article L. 262-35 du code de l'action sociale et des familles, les références : «, 282, 334 » sont supprimées.

\section{Article 25}

Le code général des impôts est ainsi modifié :

$1^{\circ}$ L'article 80 quater est ainsi modifié :

a) La référence : «275-1 » est remplacée par la référence : « $275 »$;

b) La référence : « ou 278 » est remplacée par les références : «, 278 ou 279-1 »;

c) La référence : « 294 » est remplacée par la référence : «373-2-3»;

$2^{\circ}$ Le premier alinéa du $2^{\circ}$ du II de l'article 156 est ainsi modifié :

a) La référence : « et 367 » est remplacée par les références : «, 367 et 767 »;

b) La référence : «275-1 » est remplacée par la référence : « $275 》$;

c) La référence : « ou 278 » est remplacée par les références : «, 278 ou 279-1 »;

d) La référence : « 294 » est remplacée par la référence : «373-2-3 》;

$3^{\circ}$ Dans la première phrase de l'article 757 A, la référence : « 294 » est remplacée par la référence : «373-2-3».

\section{Article 26}

L'article 199 octodecies du code général des impôts est ainsi modifié :

$1^{\circ}$ Dans le premier alinéa du I, les mots : «mentionnés au 1 de l'article 275 du code civil et à l'article 275-1 du même code, s'ils sont effectués » sont remplacés par les mots : " et l'attribution de biens ou de droits effectués en exécution de la prestation compensatoire dans les conditions et selon les modalités définies aux articles 274 et 275 du code civil » et, après les mots : "sur une période», sont insérés les mots : «, conformément à la convention de divorce homologuée par le juge ou au jugement de divorce, » ;

$2^{\circ}$ Le deuxième alinéa du même paragraphe est remplacé par deux alinéas ainsi rédigés : «La réduction d'impôt est égale à $25 \%$ du montant des versements effectués, des biens ou des droits attribués, retenu pour la valeur fixée dans la convention de divorce homologuée par le juge ou par le jugement de divorce, et dans la limite d'un plafond égal à 30500 EUR 
ALVES, M. V. - Uma reflexão sobre o uso das modalidades de tradução no contexto jurídico

apprécié par rapport à la période mentionnée au premier alinéa.

«Lorsque la prestation compensatoire prend la forme d'une rente conformément aux dispositions des articles 276, 278 et 279-1 du code civil, la substitution d'un capital aux arrérages futurs, versé ou attribué sur une période au plus égale à douze mois à compter de la date à laquelle le jugement prononçant la conversion est passé en force de chose jugée, ouvre également droit à la réduction d'impôt. Son assiette est alors égale au capital total reconstitué limité à 30500 EUR et retenu dans la proportion qui existe entre le capital dû à la date de la conversion et le capital total reconstitué à cette même date. Le capital total reconstitué s'entend de la valeur du capital versé ou attribué à la date de conversion, maj oré de la somme des rentes versées jusqu'au jour de la conversion et revalorisées en fonction de la variation de l'indice moyen annuel des prix à la consommation constatée entre l'année de versement de la rente et celle de la conversion. »;

$3^{\circ}$ Dans le dernier alinéa du même paragraphe :

a) Les mots : « les versements sont répartis » sont remplacés par les mots : "le versement des sommes d'argent, l'attribution de biens ou de droits s'effectuent »;

b) Les mots : «est passé » sont remplacés par les mots : « ou le jugement prononçant la conversion de rente en capital, sont passés »;

c) Les mots : " effectués au cours de l'année considérée et l'ensemble des versements » sont remplacés par les mots: " de sommes d'argent, des biens ou des droits attribués au cours de l'année considérée, et le montant total du capital tel que celui-ci a été fixé dans le jugement de divorce ou le jugement prononçant la conversion »;

d) Les mots : « réaliser sur la période visée » sont remplacés par les mots : "effectuer sur la période mentionnée »;

$4^{\circ}$ Au début du II, sont insérés les mots : "Nonobstant la situation visée au troisième alinéa, ».

\section{Article 27}

Le deuxième alinéa de l'article 862 du code général des impôts est complété par les mots: « ainsi que les copies exécutoires des jugements de divorce rendus en application de l'article 232 du code civil ».

\section{Article 28}

Le code général des impôts est ainsi modifié :

$1^{\circ}$ Après l'article 1133 bis, il est inséré un article 1133 ter ainsi rédigé :

«Art. 1133 ter. - Sous réserve de l'application de l'imposition prévue à l'article 1020 du présent code, les versements en capital effectués en application des articles 274, 278 et 279-1 du code civil et qui ne sont pas soumis aux dispositions de l'article 80 quater du présent code sont assujettis, lorsqu'ils proviennent de biens autres que ceux visés à I'article 748, à la perception d'une imposition fixe de 75 EUR.

« Ces dispositions sont applicables aux conversions en capital effectuées en application des articles $276-4$ et 280 du code civil. »; 
ALVES, M. V. - Uma reflexão sobre o uso das modalidades de tradução no contexto jurídico

$2^{\circ}$ Les deux dernières phrases de l'article 757 A sont supprimées ;

$3^{\circ}$ Dans la première phrase de l'article 1020, la référence : « et 1133 » est remplacée par les références: «, 1133 et 1133 ter ».

\section{Article 29}

II est inséré, après l'article 9-2 de la loi n 91-647 du 10 juillet 1991 relative à l'aide juridique, un article 9-3 ainsi rédigé :

« Art. 9-3. - Lorsque le pourvoi en cassation est susceptible d'entraîner l'annulation d'une décision ayant fixé une indemnité de licenciement, le montant de cette indemnité est exclu de l'appréciation des ressources. »

\section{Article 30}

Après l'article 66 de la loi n 91-650 du 9 juillet 1991 portant réforme des procédures civiles d'exécution, il est inséré un article 66-1 ainsi rédigé :

«Art. 66-1. - Les articles 62, 65 et 66 de la présente loi ainsi que les articles L. 613-1 à L. 613-5 du code de la construction et de I'habitation ne sont pas applicables à l'expulsion du conjoint violent ordonnée par le juge aux affaires familiales sur le fondement de l'article 220-1 du code civil. »

\section{Article 31}

Sans préjudice de l'application des délais mentionnés à l'article 267-1 du code civil, dans les départements du Bas-Rhin, du Haut-Rhin et de la Moselle, la procédure est, à compter de la désignation du notaire, soumise aux dispositions du titre VI de la loi du ler juin 1924 mettant en vigueur la législation civile française dans les départements du Bas-Rhin, du Haut-Rhin et de la Moselle.

\section{Article 32}

I. - La présente loi est applicable en Nouvelle-Calédonie, en Polynésie française, à Walliset-Futuna et à Mayotte.

II. - L'article 52-3 de la loi n²001-616 du 11 juillet 2001 relative à Mayotte est ainsi rédigé

«Art. 52-3. - Les dispositions du code civil relatives au divorce et à la séparation de corps sont applicables à Mayotte aux personnes relevant du statut civil de droit local accédant à l'âge requis pour se marier à compter du ler janvier 2005. »

III. - Après l'article 2290 du code civil, il est inséré un article 2290-1 ainsi rédigé :

«Art. 2290-1. - Les dispositions du titre VI du livre ler sont applicables à Mayotte aux 
ALVES, M. V. - Uma reflexão sobre o uso das modalidades de tradução no contexto jurídico

personnes relevant du statut civil de droit local accédant à l'âge requis pour se marier à compter du ler janvier 2005. »

\section{Article 33}

I. - La présente loi entrera en vigueur le ler janvier 2005.

II. - Elle s'appliquera aux procédures en divorce introduites avant son entrée en vigueur sous les exceptions qui suivent :

a) Lorsque la convention temporaire a été homologuée avant l'entrée en vigueur de la présente loi, l'action en divorce est poursuivie et jugée conformément à la loi ancienne ;

b) Lorsque l'assignation a été délivrée avant I'entrée en vigueur de la présente loi, I'action en divorce est poursuivie et jugée conformément à la loi ancienne.

Par dérogation au b, les époux peuvent se prévaloir des dispositions des articles 247 et 2471 du code civil ; le divorce peut également être prononcé pour altération définitive du lien conjugal si les conditions de l'article 238 sont réunies et dans le respect des dispositions de l'article 246.

III. - Les dispositions du II sont applicables aux procédures en séparation de corps.

IV. - L'appel et le pourvoi en cassation sont formés, instruits et jugés selon les règles applicables lors du prononcé de la décision de première instance.

V. - Les demandes de conversion sont formées, instruites et jugées conformément aux règles applicables lors du prononcé de la séparation de corps.

$\mathrm{VI}$. - Les rentes viagères fixées par le juge ou par convention avant l'entrée en vigueur de la loi $n^{\circ}$ 2000-596 du 30 juin 2000 relative à la prestation compensatoire en matière de divorce peuvent être révisées, suspendues ou supprimées à la demande du débiteur ou de ses héritiers lorsque leur maintien en l'état procurerait au créancier un avantage manifestement excessif au regard des critères posés à l'article 276 du code civil.

L'article 276-3 de ce code est applicable à la révision, à la suspension ou la suppression des rentes viagères fixées par le juge ou par convention avant l'entrée en vigueur de la présente loi.

La substitution d'un capital aux rentes viagères fixées par le juge ou par convention avant l'entrée en vigueur de la présente loi peut être demandée dans les conditions fixées à I'article 276-4 du même code.

VII. - Les rentes temporaires fixées par le juge ou par convention avant l'entrée en vigueur de la présente loi peuvent être révisées, suspendues ou supprimées en cas de changement important dans les ressources ou les besoins de l'une ou l'autre des parties. Leur révision ne peut conduire à proroger leur durée initiale, sauf accord des parties. La révision ne peut avoir pour effet de porter la rente à un montant supérieur à celui fixé initialement par le juge.

La substitution d'un capital aux rentes temporaires fixées par le juge ou par convention avant l'entrée en vigueur de la présente loi peut être demandée dans les conditions prévues à l'article 276-4 du code civil.

VIII. - Les prestations compensatoires fixées par le juge ou par convention avant l'entrée en vigueur de la présente loi sous la forme prévue au premier alinéa de l'article 275 du code civil, tel qu'il résulte de l'article 6 , peuvent être révisées dans les conditions prévues par le 
ALVES, M. V. - Uma reflexão sobre o uso das modalidades de tradução no contexto jurídico

deuxième alinéa de ce même article.

IX. - Les VI et VII sont applicables aux instances en cours qui n'ont pas donné lieu à une décision passée en force de chose jugée.

X. - Les dispositions des articles 280 à $280-2$ du code civil, tel qu'il résulte de l'article 6 , sont applicables aux prestations compensatoires allouées avant l'entrée en vigueur de la présente loi sauf lorsque la succession du débiteur a donné lieu à partage définitif à cette date. Dans ce dernier cas, les dispositions prévues aux deuxième et troisième alinéas du VI, au VII et au VIII sont applicables aux héritiers du débiteur. Ceux-ci peuvent également se libérer à tout moment du solde du capital indexé lorsque la prestation compensatoire prend la forme prévue au premier alinéa de l'article 275 du code civil, tel qu'il résulte de l'article 6.

XI. - Les pensions de réversion versées du chef du conjoint décédé avant la date d'entrée en vigueur de la loi n²000-596 du 30 juin 2000 précitée peuvent être, sur décision du juge saisi par les héritiers du débiteur de la prestation compensatoire, déduites du montant des rentes en cours.

\section{Article 34}

Dans l'article 61 de la loi n²001-616 du 11 juillet 2001 précitée, les mots : « des parties » sont remplacés par les mots : « de la partie la plus diligente ».

\section{Article 35}

L'article 64 de la loi n²001-616 du 11 juillet 2001 précitée est abrogé. La présente loi sera exécutée comme loi de l'Etat.

Fait à Paris, le 26 mai 2004.

J acques Chirac

Par le Président de la République :

Le Premier ministre,

J ean-Pierre Raffarin

Le garde des sceaux, ministre de la justice,

Dominique Perben

TradTerm, São Paulo, v. 24, Dezembro/ 2014, pp. 83-125

www. usp.br/tradterm

http:// www. revistas. usp. br/ tradterm/ index 
ALVES, M. V. - Uma reflexão sobre o uso das modalidades de tradução no contexto jurídico

La ministre de la famille et de l'enfance,

\author{
Marie-J osée Roig \\ La ministre de l'outre-mer, \\ Brigitte Girardin \\ La ministre de la parité \\ et de l'égalité professionnelle, \\ Nicole Ameline
}

(1) Travaux préparatoires : loi n²004-439.

Sénat :

Projet de loi $n^{\circ} 389$ (2002-2003) ;

Rapport de M. Patrice Gélard, au nom de la commission des lois, nº 120 (2003-2004) ;

Rapport d'information de Mme J anine Rozier, au nom de la délégation aux droits des femmes, $n^{\circ} 117(2003-2004)$;

Discussion les 7 et 8 janvier 2004 et adoption, après déclaration d'urgence, le 8 janvier 2004.

Assemblée nationale :

Projet de loi, adopté par le Sénat, $n^{\circ} 1338$;

Rapport de M. Patrick Delnatte, au nom de la commission des lois, $n^{\circ} 1513$;

Rapport d'information de Mme Geneviève Levy, au nom de la délégation aux droits des femmes, $n^{\circ} 1486$;

Discussion les 13 et 14 avril 2004 et adoption le 14 avril 2004.

Sénat :

Projet de loi, modifié par l'Assemblée nationale, nº 270 (2003-2004) ;

Rapport de M. Patrice Gélard, au nom de la commission mixte paritaire, $\mathrm{n}^{\circ} 280$ (2003-2004) ; 
ALVES, M. V. - Uma reflexão sobre o uso das modalidades de tradução no contexto jurídico

Discussion et adoption le 6 mai 2004.

Assemblée nationale :

Rapport de M. Patrick Delnatte, au nom de la commission mixte paritaire, $n^{\circ} 1579$;

Discussion et adoption le 12 mai 2004.

ANEXO II

\section{LEI № 6.515, DE 26 DE DEZEMBRO DE 1977.}

Regula os casos de dissolução da sociedade conjugal e do casamento, seus efeitos e respectivos processos, e dá outras providências

O PRESIDENTE DA REPÚBLICA, faço saber que o CONGRESSO NACIONAL decreta e eu sanciono a seguinte Lei:

Art 10 - A separação judicial, a dissolução do casamento, ou a cessação de seus efeitos civis, de que trata a Emenda Constitucional no 9, de 28 de junho de 1977, ocorrerão nos casos e segundo a forma que esta Lei regula.

CAPÍTULO I

DA DISSOLUÇÃO DA SOCIEDADE CONJ UGAL

Art 2o - A Sociedade Conjugal termina:

I - pela morte de um dos cônjuges;

II - pela nulidade ou anulação do casamento;

III - pela separação judicial;

IV - pelo divórcio.

Parágrafo único - O casamento válido somente se dissolve pela morte de um dos cônjuges ou pelo divórcio.

$$
\text { SEÇÃO I }
$$

Dos Casos e Efeitos da Separação J udicial

Art 3o - A separação judicial põe termo aos deveres de coabitação, fidelidade recíproca e ao regime matrimonial de bens, como se o casamento fosse dissolvido. 
ALVES, M. V. - Uma reflexão sobre o uso das modalidades de tradução no contexto jurídico

§ 1 - - O procedimento judicial da separação caberá somente aos cônjuges, e, no caso de incapacidade, serão representados por curador, ascendente ou irmão.

$\S 2^{0}$ - O juiz deverá promover todos os meios para que as partes se reconciliem ou transijam, ouvindo pessoal e separadamente cada uma delas e, a seguir, reunindo-as em sua presença, se assim considerar necessário.

§ 3 - Após a fase prevista no parágrafo anterior, se os cônjuges pedirem, os advogados deverão ser chamados a assistir aos entendimentos e deles participar.

Art 4 - Dar-se-á a separação judicial por mútuo consentimento dos cônjuges, se forem casados há mais de 2 (dois) anos, manifestado perante o juiz e devidamente homologado.

Art 50 - A separação judicial pode ser pedida por um só dos cônjuges quando imputar ao outro conduta desonrosa ou qualquer ato que importe em grave violação dos deveres do casamento e tornem insuportável a vida em comum.

\$10. A separação judicial pode, também, ser pedida se um dos cônjuges provara ruptura da vida em comum há mais de 5 (cinco) anos consecutivos, e a impossibilidade de sua reconstituição.

$\S 1^{\circ}$ A separação judicial pode, também, ser pedida se um dos cônjuges provar a ruptura da vida em comum há mais de um ano consecutivo, e a impossibilidade de sua reconstituição. (Redação dada pela Lei № 8.408, de 1992)

$\S 2^{\circ}$ - O cônjuge pode ainda pedir a separação judicial quando o outro estiver acometido de grave doença mental, manifestada após o casamento, que torne impossível a continuação da vida em comum, desde que, após uma duração de 5 (cinco) anos, a enfermidade tenha sido reconhecida de cura improvável.

§ 3ㅇ- Nos casos dos parágrafos anteriores, reverterão, ao cônjuge que não houver pedido a separação judicial, os remanescentes dos bens que levou para o casamento, e, se o regime de bens adotado o permitir, também a meação nos adquiridos na constância da sociedade conjugal.

Art 60 - Nos casos dos $\S \S 10$ e 2 do artigo anterior, a separação judicial poderá ser negada, se constituir respectivamente, causa de agravamento das condições pessoais ou da doença do outro cônjuge, ou determinar, em qualquer caso, conseqüências morais de excepcional gravidade para os filhos menores.

Art 70 - A separação judicial importará na separação de corpos e na partilha de bens. $\underline{(P C)}$.

$\S 1$ - A separação de corpos poderá ser determinada como medida cautelar (art. 796 do

$\S 2^{\circ}$ - A partilha de bens poderá ser feita mediante proposta dos cônjuges e homologada pelo juiz ou por este decidida.

Art 8 - A sentença que julgar a separação judicial produz seus efeitos à data de seu trânsito em julgado, o à da decisão que tiver concedido separação cautelar.

SEÇÃO ॥

TradTerm, São Paulo, v. 24, Dezembro/2014, pp. 83-125

www. usp.br/tradterm

http:// www. revistas. usp. br/ tradterm/ index 
ALVES, M. V. - Uma reflexão sobre o uso das modalidades de tradução no contexto jurídico

Da Proteção da Pessoa dos Filhos

Art 9 - No caso de dissolução da sociedade conjugal pela separação judicial consensual (art. 4ํ), observar-se-á o que os cônj uges acordarem sobre a guarda dos filhos.

Art 10 - Na separação judicial fundada no " caput " do art. 5ํ, os filhos menores ficarão com o cônjuge que a e não houver dado causa.

$\S 1$ - Se pela separação judicial forem responsáveis ambos os cônj uges; os filhos menores ficarão em poder da mãe, salvo se o juiz verificar que de tal solução possa adv prejuízo de ordem moral para eles.

$\S 2$ - Verificado que não devem os filhos permanecer em poder da mãe nem do pai, deferirá o juiz a sua guarda a pessoa notoriamente idônea da família de qualquer dos cônjuges.

Art 11 - Quando a separação judicial ocorrer com fundamento no $\S 10$ do art. 5o, os filhos ficarão em poder do cônjuge em cuja companhia estavam durante o tempo de ruptura da vida em comum.

Art 12 - Na separação judicial fundada no $\S 2^{\circ}$ do art. 5으 o juiz deferirá a entrega dos filhos ao cônjuge que estiver em condições de assumir, normalmente, a responsabilidade de sua guarda e educação.

Art 13 - Se houver motivos graves, poderá o juiz, em qualquer caso, a bem dos filhos, regular por maneira diferente da estabelecida nos artigos anteriores a situação deles com os pais.

Art 14 - No caso de anulação do casamento, havendo filhos comuns, observar-se-á o disposto nos arts. 10 e 13.

Parágrafo único - Ainda que nenhum dos cônjuges esteja de boa fé ao contrair o casamento, seus efeitos civis aproveitarão aos filhos comuns.

Art 15 - Os pais, em cuja guarda não estejam os filhos, poderão visitá-los e tê-los em sua companhia, segundo fixar o juiz, bem como fiscalizar sua manutenção e educação.

Art 16 - As disposições relativas à guarda e à prestação de alimentos aos filhos menores estendem-se aos filhos maiores inválidos.

$$
\text { SEÇÃO III }
$$

Do Uso do Nome

Art 17 - Vencida na ação de separação judicial (art. 50 " caput "), voltará a mulher a usar o nome de solteira.

$\S 1$ - Aplica-se, ainda, o disposto neste artigo, quando é da mulher a iniciativa da separação judicial com fundamento nos $\S \S 10$ e 20 do art. $5 \circ$.

§ 2ำ- Nos demais casos, caberá à mulher a opção pela conservação do nome de casada. 
ALVES, M. V. - Uma reflexão sobre o uso das modalidades de tradução no contexto jurídico

Art 18 - Vencedora na ação de separação judicial (art. 50 " caput "), poderá a mulher renunciar, a qualquer momento, o direito de usar o nome do marido.

\section{SEÇÃO IV}

\section{Dos Alimentos}

Art 19 - O cônjuge responsável pela separação judicial prestará ao outro, se dela necessitar, a pensão que o juiz fixar.

Art 20 - Para manutenção dos filhos, os cônjuges, separados judicialmente, contribuirão na proporção de seus recursos.

Art 21 - Para assegurar o pagamento da pensão alimentícia, o juiz poderá determinar a constituição de garantia real ou fidejussória.

$\S 1$ 으 - Se o cônjuge credor preferir, o juiz poderá determinar que a pensão consista no usufruto de determinados bens do cônjuge devedor.

§ 2o - Aplica-se, também, o disposto no parágrafo anterior, se o cônjuge credor justificar a possibilidade do não recebimento regular da pensão.

Art 22 - Salvo decisão judicial, as prestações alimentícias, de qualquer natureza, serão corrigidas monetariamente na forma dos índices de atualização das Obrigações Reajustáveis do Tesouro Nacional - ORTN.

Parágrafo único - No caso do não pagamento das referidas prestações no vencimento, o devedor responderá, ainda, por custas e honorários de advogado apurados simultaneamente.

Art 23 - A obrigação de prestar alimentos transmite-se aos herdeiros do devedor, na forma do art. 1.796 do Código Civil.

\section{CAPÍTULO II}

\section{DO DIVÓRCIO}

Art 24 - 0 divórcio põe termo ao casamento e aos efeitos civis do matrimônio religioso.

Parágrafo único - O pedido somente competirá aos cônjuges, podendo, contudo, ser exercido, em caso de incapacidade, por curador, ascendente ou irmão.

Art 25- A conversão em divórcio da separação judicial dos cônjuges, existente há mais de três anos, contada da data da decisão ou da que concedeu a medida cautelar correspondente (art. 80), será decretada por sentença, da qual não constará referência à causa que a determinou.

Art. 25. A conversão em divórcio da separação judicial dos cônjuges existente há mais de um ano, contada da data da decisão ou da que concedeu a medida cautelar correspondente $\left(\operatorname{art} .8^{\circ}\right)$, será decretada por sentença, da qual não constará referência à causa que a determinou. (Redação dada pela Lei no 8.408, de 1992) 
ALVES, M. V. - Uma reflexão sobre o uso das modalidades de tradução no contexto jurídico

Parágrafo único. A sentença de conversão determinará que a mulher volte a usar o nome que tinha antes de contrair matrimônio, só conservando o nome de família do exmarido se alteração prevista neste artigo acarretar:(Incluído pela Lei № 8.408, de 1992)

I - evidente prejuízo para a sua identificação; $\quad$ (Incluído pela Lei no 8.408, de 1992)

II - manifesta distinção entre o seu nome de família e dos filhos havidos da união dissolvida; $\quad$ (Incluído pela Lei ํㅡ 8.408, de 1992) 1992)

III - dano grave reconhecido em decisão judicial." $\quad$ (Incluído pela Lei ำ 8.408, de

Art 26 - No caso de divórcio resultante da separação prevista nos $\S \S 1$ e 2 do art. 5ํ, 0 cônjuge que teve a iniciativa da separação continuará com o dever de assistência ao outro. (Código Civil - art. 231, № III).

Art 27 - 0 divórcio não modificará os direitos e deveres dos pais em relação aos filhos.

Parágrafo único - O novo casamento de qualquer dos pais ou de ambos também não importará restrição a esses direitos e deveres.

Art 28 - Os alimentos devidos pelos pais e fixados na sentença de separação poderão ser alterados a qualquer tempo.

Art 29 - O novo casamento do cônjuge credor da pensão extingüirá a obrigação do cônjuge devedor.

Art 30 - Se o cônjuge devedor da pensão vier a casar-se, o novo casamento não alterará sua obrigação.

Art 31 - Não se decretará o divórcio se ainda não houver sentença definitiva de separação judicial, ou se esta não tiver decidido sobre a partilha dos bens.

Art 32 - A sentença definitiva do divórcio produzirá efeitos depois de registrada no Registro Público competente.

Art 33 - Se os cônjuges divorciados quiserem restabelecer a união conjugal só poderão fazê-lo mediante novo casamento.

\section{CAPÍTULO III}

\section{DO PROCESSO}

Art 34 - A separação judicial consensual se fará pelo procedimento previsto nos arts.

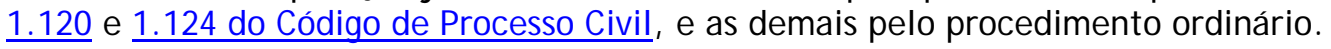

$\S 1$ - A petição será também assinada pelos advogados das partes ou pelo advogado escolhido de comum acordo.

§ 2ㅇ - 0 juiz pode recusar a homologação e não decretar a separação judicial, se comprovar que a convenção não preserva suficientemente os interesses dos filhos ou de um dos cônjuges. 
ALVES, M. V. - Uma reflexão sobre o uso das modalidades de tradução no contexto jurídico

$\S$ 3o - Se os cônjuges não puderem ou não souberem assinar, é lícito que outrem o faça a rogo deles.

$\S 4$ - Às assinaturas, quando não lançadas na presença do juiz, serão, obrigatoriamente, reconhecidas por tabelião.

Art 35 - A conversão da separação judicial em divórcio será feita mediante pedido de qualquer dos cônjuges.

Parágrafo único - 0 pedido será apensado aos autos da separação judicial. (art. 48)

Art 36 - Do pedido referido no artigo anterior, será citado o outro cônj uge, em cuj a resposta não caberá reconvenção.

Parágrafo único - A contestação só pode fundar-se em:

L- falta de decurso do prazo de 3 (três) anos de separação judicial;

I - falta do decurso de 1 (um) ano da separação judicial; $\quad$ (Redação dada pela Lei no $\underline{7.841 \text {, de 1989) }}$

II - descumprimento das obrigações assumidas pelo requerente na separação.

Art 37 - 0 juiz conhecerá diretamente do pedido, quando não houver contestação ou necessidade de produzir prova em audiência, e proferirá sentença dentro em 10 (dez) dias.

$\S 1$ - A sentença limitar-se-á à conversão da separação em divórcio, que não poderá ser negada, salvo se provada qualquer das hipóteses previstas no parágrafo único do artigo anterior.

$\S 2^{\circ}$ - A improcedência do pedido de conversão não impede que o mesmo cônj uge 0 renove, desde que satisfeita a condição anteriormente descumprida.

Art 38-O pedido de divórcio, em qualquer dos seus casos, somente poderá ser formulado uma vez. $\quad$ (Revogado pela Lei o 7.841, de 1989)

Art 39 - O capítulo III do Título II do Livro IV do Código de Processo Civil, as expressões "desquite por mútuo consentimento", "desquite" e "desquite litigioso" são substituídas por "separação consensual" e "separação judicial".

\section{CAPÍTULO IV}

\section{DAS DISPOSIÇÕES FINAIS E TRANSITÓRIAS}

Art 40- No caso de separação de fato, com início anterior a 28 de junho de 1977 , e desde que completados 5 (cinco) anos, poderá ser promovida ação de divórcio, na qual-se deverão provar 0 decurso do tempo da separação e a sua causa.

Art. 40. No caso de separação de fato, e desde que completados 2 (dois) anos consecutivos, poderá ser promovida ação de divórcio, na qual deverá ser comprovado decurso do tempo da separação. $\quad$ (Redação dada pela Lei no 7.841, de 1989) 
ALVES, M. V. - Uma reflexão sobre o uso das modalidades de tradução no contexto jurídico

§ 10-O divórcio, com base neste artigo, só poderá ser fundado nas mesmas causas previstas nos artigos $4^{\circ}$ e $5^{\circ}$ e seus parágrafos. $\quad$ (Revogado pela Lei $n$ 0 7.841, de 1989)

$\S 2$ - No divórcio consensual, o procedimento adotado será o previsto nos artigos 1.120 a 1.124 do Código de Processo Civil, observadas, ainda, as seguintes normas:

I - a petição conterá a indicação dos meios probatórios da separação de fato, e será instruída com a prova documental já existente;

II - a petição fixará o valor da pensão do cônjuge que dela necessitar para sua manutenção, e indicará as garantias para o cumprimento da obrigação assumida;

III - se houver prova testemunhal, ela será produzida na audiência de ratificação do pedido de divórcio a qual será obrigatoriamente realizada.

IV - a partilha dos bens deverá ser homologada pela sentença do divórcio.

§ 3o - Nos demais casos, adotar-se-á o procedimento ordinário.

Art 41 - As causas de desquite em curso na data da vigência desta Lei, tanto as que se processam pelo procedimento especial quanto as de procedimento ordinário, passam automaticamente a visar à separação judicial.

Art 42 - As sentenças já proferidas em causas de desquite são equiparadas, para os efeitos desta Lei, às de separação judicial.

Art 43 - Se, na sentença do desquite, não tiver sido homologada ou decidida a partilha dos bens, ou quando esta não tenha sido feita posteriormente, a decisão de conversão disporá sobre ela.

Art 44 - Contar-se-á o prazo de separação judicial a partir da data em que, por decisão judicial proferida em qualquer processo, mesmo nos de jurisdição voluntária, for determinada ou presumida a separação dos cônjuges.

Art 45 - Quando o casamento se seguir a uma comunhão de vida entre os nubentes, existentes antes de 28 de junho de 1977, que haja perdurado por 10 (dez) anos consecutivos ou da qual tenha resultado filhos, o regime matrimonial de bens será estabelecido livremente, não se Ihe aplicando o disposto no artigo 258, parágrafo único, no 1 , do Código Civil.

Art 46 - Seja qual for a causa da separação judicial, e o modo como esta se faça, é permitido aos cônjuges restabelecer a todo o tempo a sociedade conjugal, nos termos sem que fora constituída, contanto que o façam mediante requerimento nos autos da ação de separação.

Parágrafo único - A reconciliação em nada prejudicará os direitos de terceiros, adquiridos antes e durante a separação, seja qual for o regime de bens.

Art 47 - Se os autos do desquite ou os da separação judicial tiverem sido extraviados, ou se encontrarem em outra circunscrição judiciária, o pedido de conversão em divórcio será instruído com a certidão da sentença, ou da sua averbação no assento de casamento. 
ALVES, M. V. - Uma reflexão sobre o uso das modalidades de tradução no contexto jurídico

Art 48 - Aplica-se o disposto no artigo anterior, quando a mulher desquitada tiver domicílio diverso daquele em que se julgou o desquite.

Art 49 - Os §§ 50 e 60 do art. 70 da Lei de Introdução ao Código Civil passam a vigorar com a seguinte redação:

"Art. 70.

§ 5 - 0 estrangeiro casado, que se naturalizar brasileiro, pode, mediante expressa anuência de seu cônjuge, requerer ao juiz, no ato de entrega do decreto de naturalização, se apostile ao mesmo a adoção do regime de comunhão parcial de bens, respeitados os direitos de terceiros e dada esta adoção ao competente registro.

§ 60- 0 divórcio realizado no estrangeiro, se um ou ambos os cônjuges forem brasileiros, só será reconhecido no Brasil depois de três anos da data da sentença, salvo se houver sido antecedida de separarão judicial por igual prazo, caso em que a homologação produzirá efeito imediato, obedecidas as condições estabelecidas para a eficácia das sentenças estrangeiras no País. O Supremo Tribunal Federal, na forma de seu regimento interno, poderá reexaminar, a requerimento do interessado, decisões já proferidas em pedidos de homologação de sentenças estrangeiras de divórcio de brasileiros, a fim de que passem a produzir todos os efeitos legais."

Art 50 - São introduzidas no Código Civil as alterações seguintes:

1) "Art. 12.

I - os nascimentos, casamentos, separações judiciais, divórcios e óbitos."

2) "Art. 180.

V - certidão de óbito do cônjuge falecido, da anulação do casamento anterior ou do registro da sentença de divórcio."

3) "Art. 186 - Discordando eles entre si, prevalecerá a vontade paterna, ou, sendo o casal separado, devorciado ou tiver sido o seu casamento anulado, a vontade do cônjuge, com quem estiverem os filhos."

4) "Art. 195.

VII - o regime do casamento, com a declaração data e do cartório em cuj as notas foi passada a escritura antenupcial, quando o regime não for o de comunhão parcial, ou o legal estabelecido no Titulo III deste livro, para outros casamentos."

5) "Art. 240 - A mulher, com o casamento, assume a condição de companheira, consorte e colaboradora do marido nos encargos de família, cumprindo-Ihe velar pela direção material e moral desta.

Parágrafo único - A mulher poderá acrescer ao seus os apelidos do marido."

6) "Art. 248.

VIII - propor a separação judicial e o divórcio."

TradTerm, São Paulo, v. 24, Dezembro/ 2014, pp. 83-125

www. usp. br/tradterm

http:// www. revistas. usp. br/ tradterm/ index 
ALVES, M. V. - Uma reflexão sobre o uso das modalidades de tradução no contexto jurídico

7) "Art. 258 - Não havendo convenção, ou sendo nula, vigorará, quanto aos bens entre os cônjuges, o regime de comunhão parcial."

8) "Art. 267.

III - pela separação judicial;

IV - pelo divórcio."

9) "Art. 1.611 - A falta de descendentes ou ascedentes será deferida a sucessão ao cônjuge sobrevivente se, ao tempo da morte do outro, não estava dissolvida a sociedade conj ugal."

Art 51 - A Lei no 883, de 21 de outubro de 1949 passa a vigorar com as seguintes alterações:

1) "Art. 1ㅇ.

Parágrafo único - Ainda na vigência do casamento qualquer dos cônj uges poderá reconhecer o filho havido fora do matrimônio, em testamento cerrado, aprovado antes ou depois do nascimento do filho, e, nessa parte, irrevogável."

2) "Art. 20 - Qualquer que seja a natureza da filiação, o direito à herança será reconhecido em igualdade de condições."

3) - "Art. 4 ㅇ․

Parágrafo único - Dissolvida a sociedade conjugal do que foi condenado a prestar alimentos, quem os obteve não precisa propor ação de investigação para ser reconhecido, cabendo, porém, aos interessados o direito de impugnar a filiação."

4) "Art. 9o - O filho havido fora do casamento e reconhecido pode ser privado da herança nos casos dos arts. 1.595 e 1.744 do Código Civil."

Art 52 - 0 no I do art. 100, o № II do art. 155 e o § 2으 do art. 733 do Código de Processo Civil passam a vigorar com a seguinte redação:

"Art. 100.

I - da residência da mulher, para a ação de separação dos cônjuges e a conversão desta em divórcio, e para a anulação de casamento.

Art. 155.

II - que dizem respeito a casamento, filiação, separação dos cônjuges, conversão desta em divórcio, alimentos e guarda de menores."

"Art. 733.

$\S 2$ - O O cumprimento da pena não exime o devedor do pagamento das prestações vencidas e vincendas."

Art 53 - A presente Lei entrará em vigor na data de sua publicação.

TradTerm, São Paulo, v. 24, Dezembro/ 2014, pp. 83-125

www. usp. br/tradterm

http:// www. revistas. usp. br/ tradterm/ index 
ALVES, M. V. - Uma reflexão sobre o uso das modalidades de tradução no contexto jurídico

Art 54 - Revogam-se os arts. 315 a $\underline{328}$ e 0 §1ㅇdo art. 1605 do Código Civil e as demais disposições em contrário.

Brasília, em 26 de dezembro de 1977; 1560 da Independência e 89 da República.

ERNESTO GEISEL

Armando Falcão

Este texto não substitui o publicado no DOU de 27.12.1977

TradTerm, São Paulo, v. 24, Dezembro/2014, pp. 83-125

www. usp.br/ tradterm

http:// www. revistas. usp. br/ tradterm/ index 